\title{
Who believes in the storybook image of the scientist?
}

Coosje L. S. Veldkamp ${ }^{1 *}$, Chris H. J. Hartgerink ${ }^{1}$, Marcel A. L. M. van Assen ${ }^{1,2}$, and Jelte M. Wicherts $^{1}$

${ }^{1}$ Department of Methodology and Statistics, Tilburg School of Social and Behavioral Sciences, Tilburg University, Tilburg, The Netherlands.

${ }^{2}$ Department of Sociology, Faculty of Social and Behavioral Sciences, Utrecht University, Utrecht, The Netherlands

*Correspondence concerning this article should be addressed to Coosje L. S. Veldkamp, Department of Methodology and Statistics, Tilburg School f Social and Behavioral Sciences, PO Box 90153, Warandelaan 2, 5000 LE Tilburg, The Netherlands. Email address:

C.L.S.Veldkamp@ tilburguniversity.edu.

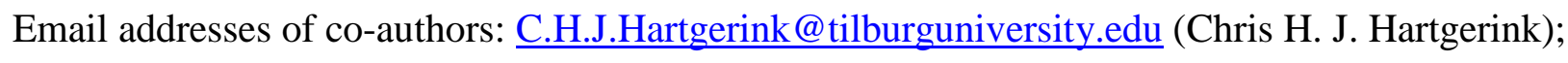

M.A.L.M.vanAssen@tilburguniversity.edu (Marcel A. L. M. van Assen);

J.M.Wicherts@tilburguniversity.edu (Jelte M. Wicherts). 
Data availability: The data reported in this paper and all materials and analysis scripts are archived at the Open Science Framework and can be accessed through https://osf.io/756ea/. The pre-registration of this study can be found through https://osf.io/z3xt6/.

Ethics Statement: this line of studies was approved by the psychology ethics (PETC) of the Tilburg School of Social and Behavioral Sciences under number EC-2014.09. Respondents provided informed consent by ticking 'yes' at the statement 'I have read and understood the above and agree to participate' on the introductory page of the studies.

Acknowledgements: we thank Jolanda Jetten, Melissa Anderson, Marjan Bakker, Paulette Flore, Hilde Augusteijn, Michèle Nuijten, and Robbie van Aert for their helpful comments on earlier versions of this manuscript.

Source of support: This research was supported by The Innovational Research Incentives Scheme Vidi from the Netherlands Organization for Scientific Research (grant number 452-11004). Website: (http://www.nwo.nl/en). The funders had no role in study design, data collection and analysis, decision to publish, or preparation of the manuscript. The authors declare no conflicts of interest.

Running head: The storybook image 


\begin{abstract}
Do lay people and scientists themselves recognize that scientists are human and therefore prone to human fallibilities such as error, bias, and even dishonesty? In a series of three experimental studies and one correlational study (total $\mathrm{N}=3,278$ ) we found that the 'storybook image of the scientist' is pervasive: American lay people and scientists from over 60 countries attributed considerably more objectivity, rationality, open-mindedness, intelligence, integrity, and communality to scientists than other highly-educated people. Moreover, scientists perceived even larger differences than lay people did. Some groups of scientists also differentiated between different categories of scientists: established scientists attributed higher levels of the scientific traits to established scientists than to early-career scientists and $\mathrm{PhD}$ students, and higher levels to $\mathrm{PhD}$ students than to early-career scientists. Female scientists attributed considerably higher levels of the scientific traits to female scientists than to male scientists. A strong belief in the storybook image and the (human) tendency to attribute higher levels of desirable traits to people in one's own group than to people in other groups may decrease scientists' willingness to adopt recently proposed practices to reduce error, bias and dishonesty in science.
\end{abstract}


"Scientists are human, and so sometimes do not behave as they should as scientists."

An anonymous science Nobel Prize Laureate in our sample, 2014

The storybook image of the scientist is an image of a person who embodies the virtues of objectivity, rationality, intelligence, open-mindedness, integrity, and communality (Mahoney, 1976, 1979). However, to avoid placing unreasonable expectations on scientists, it is important to recognize that they are prone to human frailties, such as error, bias, and dishonesty (Feist, 1998; Mahoney, 1976; Merton, 1942; Mitroff, 1974; Nuzzo, 2015; Watson, 1938). Acknowledging scientists' fallibility can help us to develop policies, procedures, and educational programs that promote responsible research practices (Shamoo \& Resnik, 2015).

According to Mahoney, the scientist is "viewed as the paragon of reason and objectivity, an impartial genius whose visionary insights are matched only by his quiet humility"(Mahoney, 1976, p. 3). With respect to scientists' self-image, he claimed that "although somewhat more restrained in his self-portrait, the scientist tends to paint himself generously in hues of objectivity, humility, and rationality", and that "the average scientist tends to be complacently confident about his rationality and his expertise, his objectivity and his insight"'(Mahoney, 1976, p. 4). However, Mahoney never supported these claims with empirical evidence. Others had demonstrated that scientists are indeed prone to human biases (Mitroff, 1974; Rosenthal, 1966) and Mahoney himself showed that the reasoning skills of scientists were not significantly different from those of nonscientists (Mahoney \& DeMonbreun, 1977), but actual belief in the storybook image of the scientist itself has never been examined. Hence, it remains unclear to what degree lay people and scientists recognize that scientists are only human. 
Some early data suggest that the belief in the storybook image of the scientist may be strong among lay people. In a seminal study (Mead \& Metraux, 1973), the analysis of a nationwide-sample of essays written by American high school students exposed the stereotypical image of the scientist: in terms of appearance, the scientist was depicted as "a man who wears a white coat and works in a laboratory. He is elderly or middle-aged and wears glasses. He is small, sometimes small and stout, or tall and thin. He may be bald. He may wear a beard, may be unshaven and unkempt. He may be stooped and tired" (Mead \& Metraux, 1973, p. 317). In terms of traits, the scientist was depicted as "a very intelligent man - a genius or almost a genius. He has long years of expensive training - in high school, college, or technical school, or perhaps even beyond - during which he studied very hard. He is interested in his work and takes it seriously. He is careful, patient, devoted, courageous, open-minded. He knows his subject. He records his experiments carefully, does not jump to conclusions, and stands up for his ideas even when attacked [...]" (Mead \& Metraux, 1973, p. 317). A similar, male image had been found in earlier studies (e.g.Beardslee \& O'dowd, 1961) and came back in later studies (e.g. Basalla, 1976). The stereotypical image in terms of appearance consistently returned in studies using the now classic 'Draw a Scientist Test' (Beardslee \& O'dowd, 1961, p. 998; D. W. Chambers, 1983; Fort \& Varney, 1989; Newton \& Newton, 1992; ó Maoldomhnaigh \& Hunt, 1988) More recently, European and American surveys have demonstrated that lay people have a stable and strong confidence both in science (Gauchat, 2012; Smith \& Son, 2013) and in scientists (Ipsos MORI, 2014; Smith \& Son, 2013). For example, the scientific community was found to be the second most trusted institution in the US (Smith \& Son, 2013), and in the UK, the general public believed that scientists meet the expectations of honesty, ethical behavior, and open-mindedness (Ipsos MORI, 2014). 
As far as we know, no empirical work has addressed scientists' views of the scientist. Although preliminary results from Robert Pennock's 'Scientific Virtues Project' (cited in "Character traits: Scientific virtue," 2016) indicate that scientists consider honesty, curiosity, perseverance, and objectivity to be the most important virtues of a scientist, these results do not reveal whether scientists believe that the typical scientist actually exhibits these virtues. A number of studies on scientists' perceptions of research behavior suggest that scientists may not believe that the typical scientist lives up to the stereotypical image of the scientist. First, a large study among NIH-funded scientists (Anderson, Martinson, \& De Vries, 2007) found that scientists considered the behavior of their typical colleague to be more in line with unscientific norms such as secrecy, particularism, self-interestedness and dogmatism than with the traditional scientific norms of communality, universalism, disinterestedness, and organized skepticism (Merton, 1942; Mitroff, 1974). Second, a meta-analysis including studies from various fields of science showed that over $14 \%$ of scientists claimed that they had witnessed serious misconduct by their peers, and that up to $72 \%$ of scientists reported to have witnessed questionable research practices (Fanelli, 2009). Third, publication pressure and competition in science are perceived as high (Tijdink, Verbeke, \& Smulders, 2014; Tijdink, Vergouwen, \& Smulders, 2013), while scientists have expressed concerns that competition "contributes to strategic game-playing in science, a decline in free and open sharing of information and methods, sabotage of others' ability to use one's work, interference with peer-review processes, deformation of relationships, and careless or questionable research conduct" (Anderson, Ronning, De Vries, \& Martinson, 2007). Based on these reports, one would expect scientists' belief in the storybook image of the scientist to be low compared to lay people's belief. 
On the other hand, there is also reason to hypothesize that scientists do believe in the storybook image: scientists may be prone to the well-established human tendencies of in-group bias and stereotyping (Tajfel \& Turner, 1986; Turner, Hogg, Oakes, Reicher, \& Wetherell, 1987). In-group bias might lead them to evaluate scientists more positively than non-scientists, or their own group of scientists more positively than other groups of scientists and non-scientists, while stereotyping might lead scientists to believe that some scientists (e.g. elderly and/or male scientists) fit the storybook better than other scientists.

In this paper, we will address potential in-group bias and stereotyping among scientists by examining two versions of social grouping that are particularly relevant in science: the scientist's career level and his or her gender. Status differences of established scientists, earlycareer scientists and $\mathrm{PhD}$ students may be perceived as reflecting the degree to which different scientists fit the storybook image, while in-group biases may lead scientists to attribute more of the storybook characteristics to scientists of their own professional level. For instance, due to the stereotypical image of a scientists being an elderly male (Mead \& Metraux, 1973), established scientists might be viewed overall as fitting the storybook image of the scientist better than earlycareer scientists. Yet, in-group bias might lead early-career scientists to regard themselves as fitting the storybook image of the scientist better than established scientists. It is relevant to study these views among scientists because differences in how researchers view their typical colleague and their own group could play a role in the adoption of recent efforts in science aimed at dealing with human fallibilities. For instance, if established scientists view early-career scientists as being more prone to biases in their work, these established scientists might believe that programs aimed at improving responsible conduct of research should be targeted at early-career scientists, while early-career scientists themselves might feel otherwise. 
Similarly, while gender inequality in science is still a widely debated topic (Miller, Eagly, \& Linn, 2014; Shen, 2013; Sugimoto, 2013; Williams \& Ceci, 2015), male scientists may be believed to fit the storybook image better than female scientists because of the common stereotype of the scientist being male (D. W. Chambers, 1983; Hassard, 1990; Mead \& Metraux, 1973). However, at the same time in-group biases may lead scientists to attribute more of the storybook characteristics to scientists of their own gender. Knowing how male and female scientists view applicability of the storybook image of the scientist to male and female scientists could contribute to the debate on the nature and origins of gender disparities in science (Ceci \& Williams, 2011; Cress \& Hart, 2009; Shen, 2013; Sugimoto, 2013; West, Jacquet, King, Correll, \& Bergstrom, 2013).

We investigate lay people's and scientists' belief in the storybook image of the scientist in four studies. Studies 1 and 2 aimed to test whether highly-educated lay people and scientists believe the storybook characteristics of the scientist to apply more strongly to scientists than to other highly-educated people. In Study 1, we used an experimental between-subjects design to compare the perception of the typical scientist to the perception of the overall group of other highly-educated people who are not scientists, whereas in Study 2, we used a mixed design with random ordering to compare scientists with nine specific other professions that require a high level of education, like medical doctors or lawyers. We expected that both scientists and nonscientists with a high level of education would attribute higher levels of objectivity, rationality, open-mindedness, intelligence, cooperativeness, and integrity to people with the profession of scientist than to people with one of the other nine professions.

Studies 3 and 4 only involved scientist respondents and zoomed in on potential effects of in-group biases and stereotypes related to academic levels and gender. In Study 3, we used an 
experimental between-subjects design to study whether scientists overall believe that scientists of higher professional levels fit the storybook image of the scientist better than scientists of lower professional levels, as the 'elderly' stereotype prescribes. We also studied whether scientists at different career stages differ in this belief, because in-group biases might lead them to attribute more of the storybook characteristics to their own professional level.

In Study 4, we used a similar experimental between-subjects design to test the hypothesis that scientists believe that male scientists fit the storybook image of the scientist better than female scientists, as expected on the basis of the predominantly male stereotype of the scientist. Moreover, Study 4 addresses the question whether male and female scientists are prone to ingroup biases leading them to believe that the storybook characteristics apply more strongly to scientists of their own gender.

\section{Study 1}

\section{Method}

Participants. Three groups of participants participated in Study 1, constituting the variable Respondent Group. These groups are specified below.

Scientists. To obtain a representative sample of scientists, we extracted e-mail addresses of corresponding authors from scientific articles published in 2014 that were listed in the Web of Science database (Thomson Reuters, 2014). We sent out batches of e-mail invitations until we reached our desired sample sizes (see power calculations in our study pre-registration through https://osf.io/z3xt6/). Our e-mailed invitations to participate in our study yielded 1,088 fully completed responses from across the globe, of which 343 were from the United States. The response rate was $10.6 \%$ (see Table $\mathrm{S} 1$ in the supplementary materials). In order to compare 
results of scientists with results of American highly-educated lay people (see below), only responses from American scientists were used in our statistical analyses. After a priori determined outlier removal (see study pre-registration through https://osf.io/z3xt6/), we were able to use the responses of 331 American scientists (34\% female). Their mean age was 49 years $(\mathrm{SD}=11.4$, range $=26-77)$.

Highly-educated lay people. Survey software and data collection company Qualtrics provided us with 315 fully completed responses of a representative sample of highly-educated non-scientists. These respondents were members of the Qualtrics' paid research panel, and were selected on the following criteria: American citizen, aged over 18, and having obtained a Bachelor's degree, a Master's degree, or a Professional degree, but not a PhD. Response rates could not be computed for this sample, as Qualtrics advertises ongoing surveys to all its eligible panel members and terminates data collection when the required sample size is reached.

However, Qualtrics indicates that their response rate for online surveys generally approaches $8 \%$. After a priori determined outlier removal we were able to use the responses of 312 respondents ( $46 \%$ female). Their mean age was 49.2 years $(\mathrm{SD}=13.8$, range $=23-84)$.

Nobel Prize laureates. To our sample of scientists and highly-educated lay people we added a sample of scientists who might be viewed as the 'paragon of the ideal scientist': Nobel Prize laureates in the science categories. As we anticipated that the size of this additional sample would be too small to include in the statistical analyses, we decided in advance that the data of this extra sample would be used descriptively in the graphical representation of the data but not in the statistical analyses. We conducted an online search for the e-mail addresses of all Nobel Prize laureates in the science fields to date as listed on the Official Web Site of the Nobel Prize (Nobelprize.org, 2014). Our emailed invitations yielded 34 fully completed responses from 
science Nobel Prize laureates (100\% male). The response rate in this sample was $19.0 \%)$. The mean age was $75.3(\mathrm{SD}=12.7$, range $=45-93)$.

Materials and procedure. We programmed our between-subjects experimental design into an electronic questionnaire using Qualtrics software, Version March 2014 (Qualtrics, 2014). The program randomly assigned the scientist respondents and the highly-educated respondents to one of two conditions (Targets): either to a condition in which the questions pertained to the 'typical scientist' (Target 'Scientist', defined as "a person who is trained in a science and whose job involves doing scientific research or solving scientific problems"), or to a condition in which the statements pertained to the 'typical highly-educated person' (Target 'Highly-educated person', defined as “a person who obtained a Bachelor's Degree or a Master's Degree or a Professional Degree and whose job requires this high level of education"). Participating Nobel Prize laureates were always assigned to the condition in which the Target was 'Scientist'. By using a between-subjects design, we explicitly ensured that respondents did not compare the Target 'Scientist' to the Target 'Highly-educated person', but rated their Target on its own merits.

Respondents were asked to indicate on a seven-point Likert scale to what extent they agreed or disagreed with 18 statements about the objectivity, rationality, open-mindedness, intelligence, integrity, and communality (cooperativeness) of their Target (either a scientist or a highly-educated person (depending on the experimental condition to which they had been assigned). The statements were presented in randomized order. Each set of three statements constituted a small but internally consistent scale: Objectivity $(\alpha=0.73)$, Rationality $(\alpha=0.76)$, Open-mindedness $(\alpha=0.77)$, Intelligence $(\alpha=0.73)$, Integrity $(\alpha=.87)$, and Communality $(\alpha=$ 0.79). The statements were based on the 'testable hypotheses about scientists' postulated by 
Mahoney in his evaluative review of the psychology of the scientist [7] and can be found in the 'Materials'section of the supplementary materials and on our Open Science Framework page (https://osf.io/756ea/). The instructions preceding the statements emphasized that respondents should base their answers on how true they believed each statement to be, rather than on how true they believed the statement should be. Finally, all respondents were asked to answer a number of demographic questions, and were given the opportunity to answer an open question asking whether they had any comments or thoughts they wished to share.

\section{Results}

The results of Study 1 are presented in Fig. 1. In line with our expectations, there was a main effect of Target for each of the characteristics: respondents who were assigned to the Target 'Scientist' ascribed more objectivity (Cohen's $d=0.47,95 \% \mathrm{CI}=[0.31,0.63])$, rationality $(d=$ $0.63[0.48 ; 0.79])$, open-mindedness $(d=0.35[0.19 ; 0.50])$, intelligence $(d=0.44,95 \% \mathrm{CI}=$ $[0.29,0.60])$, integrity $(d=0.77,95 \% \mathrm{CI}=[0.61,0.93])$, and communality $(d=0.48,95 \% \mathrm{CI}=$ $[0.32,0.63])$ to their Target than respondents who were assigned to the Target 'Highly-educated person'. The absence of any interaction effects indicated that there was no evidence that the effects of Target were different in size in the respondent groups. In addition, there were main effects of Respondent Group: scientists on average tended to be less generous than lay people in their attributions of objectivity $(d=0.45,95 \% \mathrm{CI}=[0.29,0.60])$, intelligence $(d=0.36,95 \% \mathrm{CI}$ $=[0.21,0.52])$, and communality $(d=0.47,95 \% \mathrm{CI}=[0.31,-0.62])$, but a little more generous in their attributions of rationality $(d=0.16,95 \% \mathrm{CI}=[0.00,0.31])$ and integrity $(d=0.23,95 \% \mathrm{CI}$ $=[0.07,0.38])$. As can be seen in Fig. 1, Nobel Prize laureates tended to attribute relatively high levels of the storybook characteristics to their Target 'Scientists'. In all studies, we conducted separate analyses for each of the six storybook characteristics and employed an alpha of 
$0.008333(0.05 / 6)$ for the interaction effects or main effects. We used an alpha of 0.05 for subsequent analyses of simple effects. Detailed descriptive results for each subsample and all statistical test results can be found in supplementary Tables S1-S4.

Fig. 1. Attributions of Objectivity, Rationality, Open-mindedness, Intelligence, Integrity, and Communality to the Targets 'Highly-educated person' and 'Scientist', by Respondent Group. 

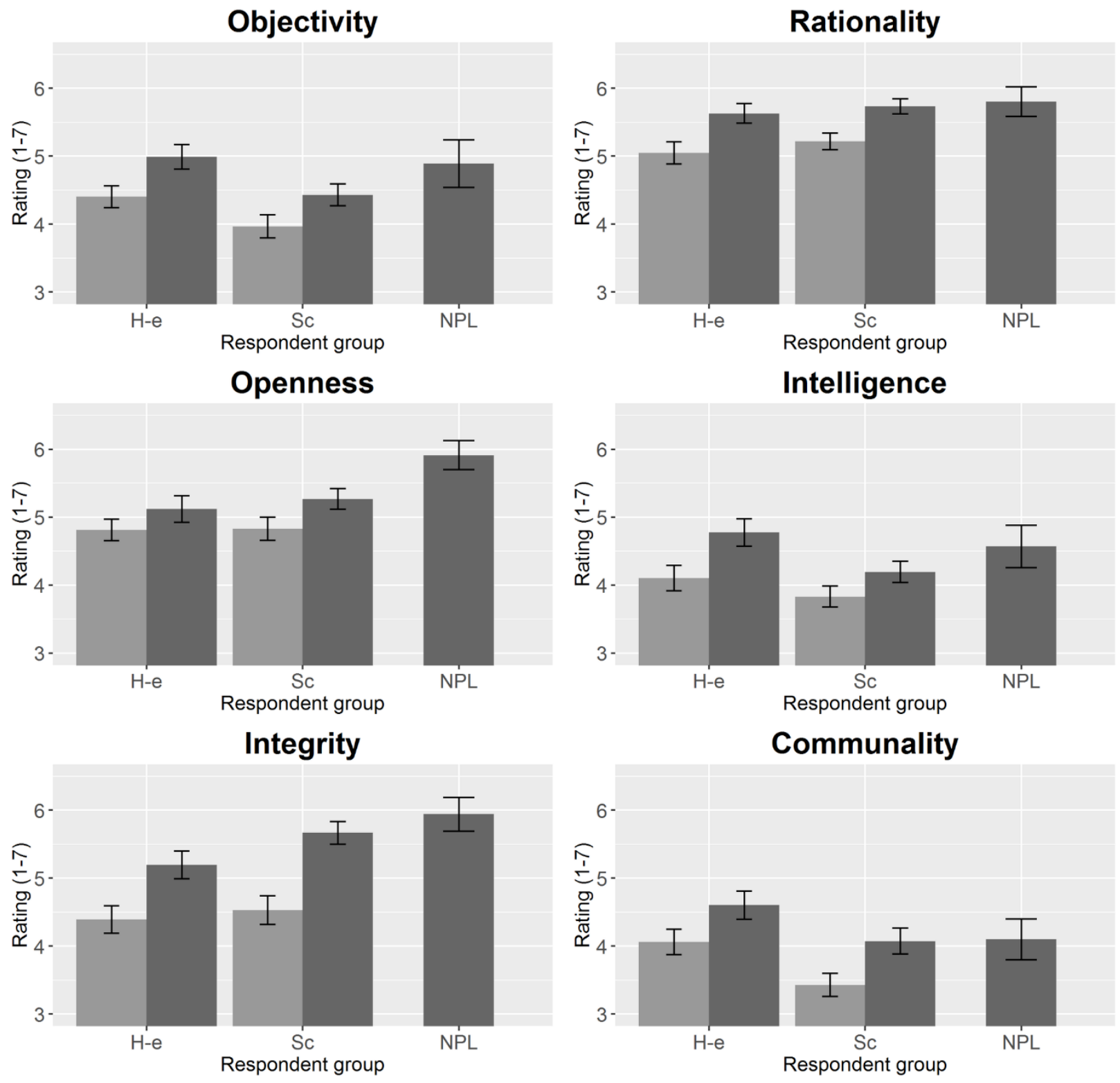

A Highly-Educated person

A scientist 
Note . H-e = Highly-educated respondent group; $\mathrm{Sc}=$ Scientist respondent group; $\mathrm{NPL}=$ Nobel Prize laureates respondent group. Nobel Prize laureates were always assigned to the Target 'Scientist'. The error bars represent $95 \%$ confidence intervals.

\section{Discussion of Study 1}

Study 1 confirmed our hypothesis that lay people perceive scientists as considerably more objective, rational, open-minded, honest, intelligent, and cooperative than other highly-educated people. We also found scientists' belief in the storybook image to be similar to lay people's belief. Comparable patterns were found among scientists from Europe $(\mathrm{N}=304)$ and Asia $(\mathrm{N}=$ 117, see Fig. S1 in the supplementary materials), indicating that the results may generalize to scientists outside the USA. Nobel laureates' ratings of the Target 'Scientist' were generally similar to, albeit somewhat higher than other scientists' ratings of the Target 'Scientist'.

One potential drawback of the design of Study 1 was that the scale may have been used differently in the two conditions; because the concept 'a highly-educated person' refers to a more heterogeneous category than the concept 'a scientist', respondents may have given more neutral scores in the 'highly-educated' condition than in the 'scientist' condition. In Study 2, we addressed this issue by examining whether similar results would be obtained when explicit comparisons were made between the profession of scientist and other specific professions that require a high level of education.

\section{Study 2}

\section{Method}


Participants. Two groups of participants participated in Study 2, constituting the variable Respondent Group. Sample sizes were smaller than in Study 1 because Study 2 employed a mixed design in which all respondents rated all targets (in a randomized order).

Scientists. We recruited a group of scientist respondents in the same manner as in Study 1. After excluding the 281 non-American responses, our method to recruit participants yielded 123 complete responses. The response rate was $11.0 \%$ (see Table S5 in the supplementary materials). After a priori determined outlier removal we were able to use the responses of 111 American scientists ( $20 \%$ female). Their mean age was 49.9 years $(\mathrm{SD}=12.4$, range $=27-85)$.

Highly-educated lay people. Qualtrics provided us with 81 fully completed responses from a representative sample of highly-educated American people. These respondents were members of the Qualtrics' paid research panel, and they were selected on the following criteria: American citizen, aged over 18, and having obtained a Bachelor's degree, a Master's degree, or a Professional degree, but not a $\mathrm{PhD}$. Response rates could not be computed for this sample, as Qualtrics advertises ongoing surveys to all its eligible panel members and terminates data collection when the required sample size is reached. However, Qualtrics indicates that their response rate for online surveys generally approaches $8 \%$. After a priori determined outlier removal we were able to use 75 of their responses ( $47 \%$ female). The mean age in this group was 46.3 years $(\mathrm{SD}=14.7$, range $=22-83)$.

Materials and procedure. We programmed a mixed between-subjects / within-subjects design into an electronic questionnaire using Qualtrics software, Version March 2014 (Qualtrics, 2014). This time, respondents were not randomly assigned to one of two conditions, but all respondents were asked how much each of the six characteristics of the ideal scientist (objectivity, rationality, open-mindedness, integrity, intelligence and communality) applied to 
ten different professions requiring a high-level education. For each of the features, respondents indicated on slider bars ranging from 0 to 100 how much they believed it applied to the typical person with the profession of lawyer, politician, journalist, medical doctor, accountant, armylieutenant, banker, judge, detective, and scientist. Respondents were explicitly instructed to indicate how much they believed each feature really applied to the typical person within this profession rather than how much the feature should apply to the typical professional in each category. We used Mahoney's (1979) antonym 'competitiveness' instead of 'communality' because we were concerned that the term 'communality' might be unclear for respondents. The characteristics were presented in random order, and within the characteristics, the professions were also presented in random order. Finally, just as in Study 1, all respondents were asked to answer a number of demographic questions and were given the opportunity to answer an open question asking whether they had any comments or thoughts they wished to share.

\section{Results}

Results of Study 2 are presented in Fig. 2. Because we were specifically interested in the overall differences in perception between the profession of the scientist and other professions that require a high level of education, we pooled the ratings of the non-scientist professions and compared these to the ratings of the scientist profession. The means of the ten different professions separately are presented in Fig. S2 in the supplementary materials and indicate that the patterns were similar across professions, justifying the pooling of their means.

Similar to Study 1, respondents attributed more objectivity, rationality, open-mindedness, intelligence, integrity, and competitiveness to scientists than to other types of professionals. However, this time, interactions qualified the effects. Follow-up analyses of the effect of Target in each Respondent Group (scientists and highly-educated lay people) indicated that scientists 
perceived greater differences between scientists and other types of professionals than lay people did. The effect sizes of the difference in attributions to scientists and to the other types of professionals were much larger in the scientist respondent group (objectivity: $d=1.76,95 \% \mathrm{CI}=$ $[1.57,1.94]$, rationality: $d=1.50,95 \% \mathrm{CI}=[1.31,1.69]$, open-mindedness: $d=1.71,95 \% \mathrm{CI}=$ $[1.52,1.90]$, intelligence: $d=1.88,95 \% \mathrm{CI}=[1.69,2.07]$, integrity: $d=1.51,95 \% \mathrm{CI}=[1.32$, 1.69], and competitiveness: $d=0.75,95 \% \mathrm{CI}=[0.56,0.93])$ than in the lay people respondent group (objectivity: $d=1.02,95 \% \mathrm{CI}=[0.79,1.25]$, rationality: $d=0.79,95 \% \mathrm{CI}=[0.56,1.02]$, open-mindedness: $d=0.63,95 \% \mathrm{CI}=[0.40,0.86]$, intelligence: $d=1.44,95 \% \mathrm{CI}=[1.21,1.67]$, integrity: $d=0.87,95 \% \mathrm{CI}=[0.64,1.10]$, and competitiveness: $d=-0.03,95 \% \mathrm{CI}=[-0.26$, 0.20]). Detailed descriptive results and statistical test results can be found in supplementary Tables S5-S8.

Fig. 2. Attributions of Objectivity, Rationality, Open-mindedness, Intelligence, Integrity, and Communality to people with highly-educated professions and people with the profession of scientist, by Respondent Group. 

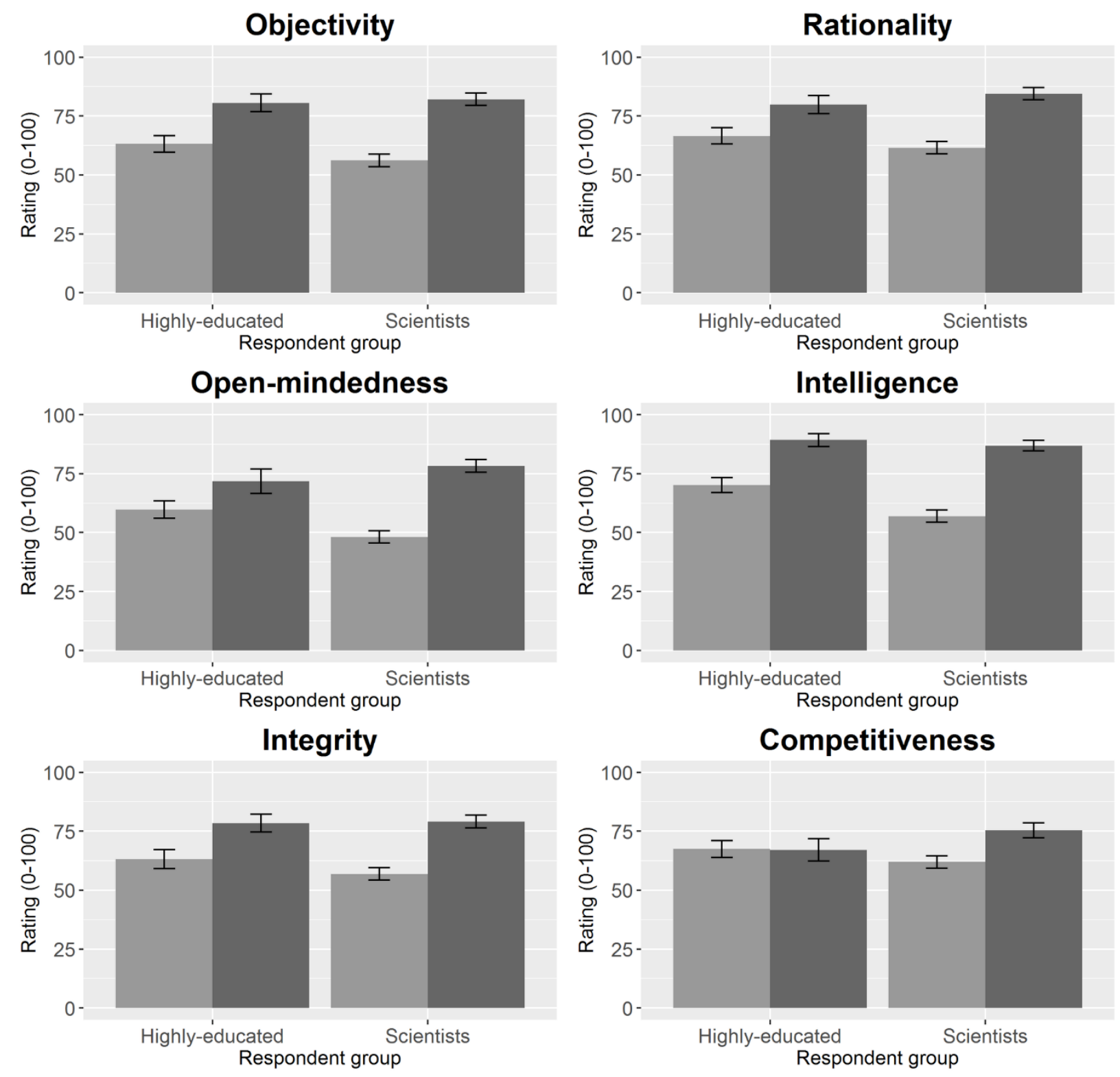

Target

Other professions

Scientists

Note. The error bars represent $95 \%$ confidence intervals. 


\section{Discussion of Study 2}

Study 2 again confirmed the hypothesis that scientists are perceived as considerably more objective, more rational, more open-minded, more honest, and more intelligent than other highlyeducated professionals. Study 2 did not confirm that scientists are perceived as more communal than other highly-educated professionals. Our choice of measuring perceived 'communality' (a potentially unclear term) through its opposite 'competitiveness' might explain the difference with Study 1, where scientists were perceived as more communal than other highly-educated people: respondents may not have perceived competitiveness as an antonym of communality.

Comparing specific professions ruled out the potential alternative explanation for the results of Study 1: that the highly-educated Target was referring to a more heterogeneous category than the scientist Target and therefore elicited more neutral responses. Again, similar patterns were found among European $(n=67)$ and Asian scientists $(n=20$, see Fig. S3 in the supplementary materials), indicating that these results may generalize beyond American scientists. While in Study 1 there was no evidence that the effect of Target was larger in one respondent group than in the other respondent group, in Study 2 we did find that the effect of Target was larger in the Scientist respondent group: scientists perceived much larger differences between people with the profession of scientist and people with other highly-educated professions than highly-educated lay respondents did.

Although our studies are not equipped to test whether any of these perceived differences between professions in attributed traits reflect actual differences in these traits, our finding that scientists rate scientists higher on the storybook traits than lay people do may be explained by ingroup biases among scientists. In-group biases, or tendencies to rate one's own group more favorably, are not expected to play any role among the heterogeneous sample of lay respondents 
(not specifically sampled to be in any of the nine remaining professions), but might have enhanced ratings of scientists among the scientists. In-group biases among scientists are further investigated in Studies 3 and 4.

\section{Study 3}

\section{Method}

Participants. We recruited an international sample of scientists in the same manner as in Studies 1 and 2. This time our method to recruit participants yielded 1,656 complete responses from scientists who fulfilled our inclusion criteria for PhD student, early-career scientist (defined as having obtained a PhD 10 years ago or less, and not having obtained tenure), or established scientist (defined as having obtained a $\mathrm{PhD}$ more than 10 years ago and having obtained tenure). The response rate was $10.6 \%$ (see Table S9 in the supplementary materials). Because the sample of $\mathrm{PhD}$ students turned out much too small compared to the size required by our sample size calculations (see online supplementary materials), we decided not to use their responses in our analyses. Because in this study we did not compare results with lay people from the US, we included responding scientists from across the globe. After removal of the $\mathrm{PhD}$ students and a priori determined removal of outliers we were able to use the responses of 515 early-career scientists from 55 countries (32\% female) and 903 established scientists from 63 countries (22\% female) in our analysis. The mean age of the early-career scientists was 35.2 years $(\mathrm{SD}=5.8$, range $=26-94)$, the mean age of the established scientists was 51.9 years $(\mathrm{SD}=9.2$, range $=35$ -90). The data of the PhD students are retained in the publicly available data file on the Open Science Framework (see https://osf.io/756ea/). 
Materials and procedure. As in Study 1, we programmed a between-subjects experimental design into an electronic questionnaire using Qualtrics software, Version March 2014 (Qualtrics, 2014). The program randomly assigned respondents to one of three conditions; either to a condition in which the statements pertained to an established scientist (Target 'Established scientist'), to a condition in which the statements pertained to an early-career scientist (Target 'Early-career scientist'), or to a condition in which the statements pertained a PhD student (Target 'PhD student'). The sets of statements again constituted sufficiently consistent scales: Objectivity $(\alpha=0.63)$, Rationality $(\alpha=0.74)$, Open-mindedness $(\alpha=0.67)$, Intelligence ( $\alpha=0.70)$, Integrity $(\alpha=.82)$, and Communality $(\alpha=0.63)$. As in the other studies, the instructions preceding the statements emphasized that respondents should base their answers on how true they believed each statement was, rather than on how true they believed the statement should be. The 18 statements were presented in randomized order. Finally, all respondents were asked to answer a number of demographic questions, and they were given the opportunity to answer an open question asking whether they had any comments or thoughts they wished to share.

\section{Results}

Results of Study 3 are presented in Fig. 3. In line with the notion of in-group biases, interactions were statistically significant for all features except intelligence and communality, indicating that effects of Target were different in the two analyzed respondent groups. Subsequent analyses of the effects in the separate respondent groups of early-career scientist respondents and established scientist respondents indicated that established scientists who were assigned to the Target 'Established scientist' attributed considerably more objectivity $(d=0.41,95 \% \mathrm{CI}=[0.25,0.57])$, rationality $(d=0.64,95 \% \mathrm{CI}=[0.48,0.81])$, open-mindedness $(d=0.62,95 \% \mathrm{CI}=[0.46,0.79])$, 
and integrity $(d=0.61,95 \% \mathrm{CI}=[0.45,0.77])$ to their Target than established scientists who were assigned to the Target 'Early-career scientist'. Established scientists who were assigned to the Target 'Established scientist' also attributed more objectivity $(d=0.30,95 \% \mathrm{CI}=[0.13$, $0.45])$, rationality $(d=0.36,95 \% \mathrm{CI}=[0.15 ; 0.58])$, open-mindedness $(d=0.42,95 \% \mathrm{CI}=[0.26$, $0.58])$, and integrity $(d=0.22,95 \% \mathrm{CI}=[0.06,0.38])$ to their Target than established scientists who were assigned to the Target ' $\mathrm{PhD}$ student'. Interestingly, established scientists who were assigned to the Target 'Early-career scientist' attributed less open-mindedness $(d=-0.23,95 \%$ $\mathrm{CI}=[-0.49,-0.07])$ and integrity $(d=-0.44,95 \% \mathrm{CI}=[-0.60,-0.27])$ to their Target than established scientists who were assigned to the Target 'PhD student'.

The effects were smaller among early-career scientists; early-career scientists who were assigned to the Target 'Early-career scientist' only attributed more objectivity $(d=0.28,95 \%$ CI $=[0.07,0.50])$ and rationality $(d=0.60,95 \% \mathrm{CI}=[0.44,0.76])$ to their Target than early-career scientists who were assigned to the Target 'PhD student', and early-career scientists who were assigned to the Target 'Established scientist' only attributed more rationality $(d=0.34,95 \% \mathrm{CI}=$ $[0.12,0.55])$ to their Target than early-career scientists who were assigned to the Target 'Earlycareer scientist'. Detailed descriptive results and statistical test results can be found in Tables S9S12.

Fig. 3. Attributions of Objectivity, Rationality, Open-mindedness, Intelligence, Integrity, and Communality to the Targets 'Established scientists', 'Early-career scientists' and 'PhD student' by Respondent Group. 

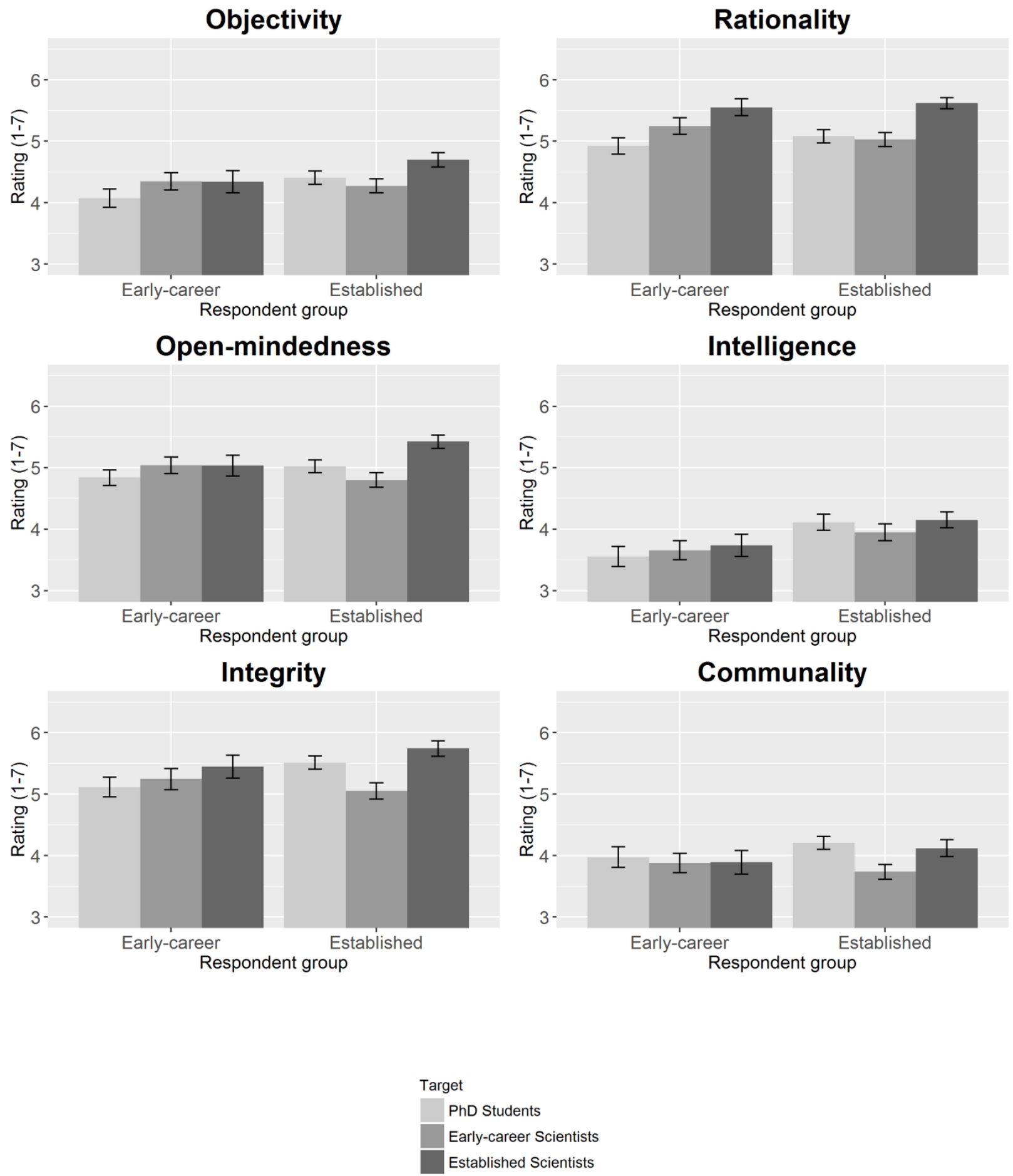

Note. The error bars represent $95 \%$ confidence intervals. 


\section{Discussion of study 3}

Study 3 partially confirmed our hypothesis that scientists, just like other human beings, are prone to in-group bias. Although stereotypes may play a role here as well, the in-group effect appears to be stronger among established scientists than among early-career scientists. This may be explained by research showing that high status group members have been found to be more prone to in-group bias than low status group members (Bettencourt, Charlton, Dorr, \& Hume, 2001). In-group biases have also been found to be stronger among people who identify more strongly with their group (Tajfel \& Turner, 1986; Turner et al., 1987), which might apply more to established scientists than to early-career scientists because they have been a scientist for a larger part of their lives.

The difference in in-group bias between early-career scientists and established scientists may also be partly explained by belief in the stereotypical image of the scientist as an old and wise person: if both early-career scientists and established scientists believe that established scientists fit the storybook image better, this would enhance the apparent in-group bias among established scientist, but not among early-career scientists. However, as the early-career scientists only agreed to some extent that established scientists fit the storybook image better than early-career scientists, the effect of the stereotypical image of the scientists cannot be fully responsible for the stronger in-group effect among established scientists. In addition, the stereotypical image of the older scientist cannot explain either why established scientists believe that in some respects, $\mathrm{PhD}$ students fit the storybook image of the scientist better than earlycareer scientists. In Study 4, we tested whether in-group bias among scientists generalize to another highly relevant form of social grouping in science: in-group bias in terms of gender. 


\section{Study 4}

\section{Method}

Participants. We recruited an international sample of scientists in the same manner as in the first three studies. This time method to recruit participants yielded 1,003 complete responses (response rate $12.0 \%$, see Table S13 in the supplementary materials). After a priori outlier removal we were able to use the responses of 711 male scientists from 63 countries (mean age $=$ $45.1, \mathrm{SD}=11.9$, range $=25-86)$ and 286 female scientists from 46 countries $($ mean age $=41.8$, $\mathrm{SD}=10.3$, range $=24-73)$.

Materials and procedure. As in Studies 1 and 3, we programmed a between-subjects experimental design into an electronic questionnaire using Qualtrics software, Version March 2014 (Qualtrics, 2014). The program randomly assigned respondents to one of two conditions; either to a condition in which the statements pertained to a female scientist (Target 'Female scientist'), or to a condition in which the statements pertained to a male scientist (Target 'Male scientist'). The sets of statements constituted sufficiently consistent scales: Objectivity $(\alpha=$ $0.58)$, Rationality ( $\alpha=0.78)$, Open-mindedness $(\alpha=0.67)$, Intelligence $(\alpha=0.62)$, Integrity $(\alpha=$ .79), and Communality $(\alpha=0.58)$. As in the other studies, the instructions preceding the statements emphasized that responders should base their answers on how true they believed each statement to be, rather than on how true they believed the statement should be. The 18 statements were presented in randomized order. Finally, all respondents were asked to answer a number of demographic questions and were given the opportunity to answer an open question asking whether they had any comments or thoughts they wished to share.

\section{Results}


The results of Study 4 are presented in Fig. 4. Interactions were significant for all features except objectivity and intelligence, indicating that the effect of Target was different for male and female respondents. Subsequent analyses of the effects for male and female respondents separately indicated that female scientists who were assigned to the condition 'Female scientist' attributed more rationality $(\mathrm{d}=0.82,95 \% \mathrm{CI}=[0.57,1.06])$, more open-mindedness $(\mathrm{d}=0.99,95 \% \mathrm{CI}=$ $[0.75,1.24])$, more integrity $(\mathrm{d}=0.69,95 \% \mathrm{CI}=[0.45,0.93])$, and much more communality $(\mathrm{d}=$ $1.13,95 \% \mathrm{CI}=[0.88,1.38])$ to their Target than female scientists who were assigned to the Target 'Male scientist'. Male scientists who were assigned to the Target 'Female scientist' attributed only somewhat more communality $(\mathrm{d}=0.35[0.20 ; 0.50])$ to their Target than male scientists who were assigned to the Target 'Male scientist'. We thus found support for in-group bias among female scientists, but not for in-group bias among male scientists. Furthermore, we found no evidence for the stereotypical notion that male scientists are believed to fit the storybook image of the scientist better than female scientists. If anything, overall, higher levels of the storybook characteristics were attributed to female scientists than to male scientists. Detailed descriptive results and statistical test results can be found in Tables S13-S16.

Fig. 4. Attributions of Objectivity, Rationality, Open-mindedness, Intelligence, Integrity, and Communality to female scientists and to male scientists, by Respondent Group. 

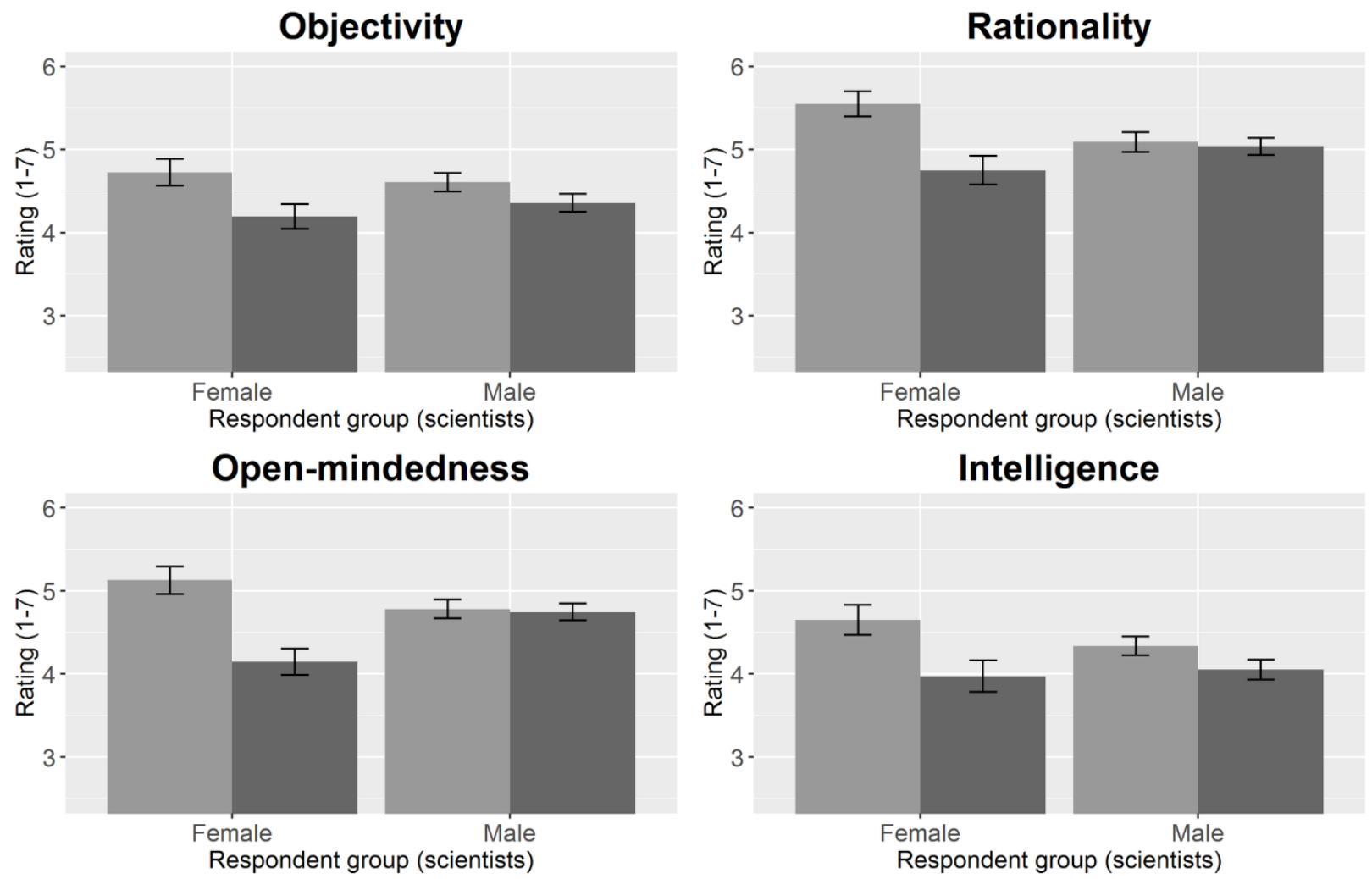

Integrity
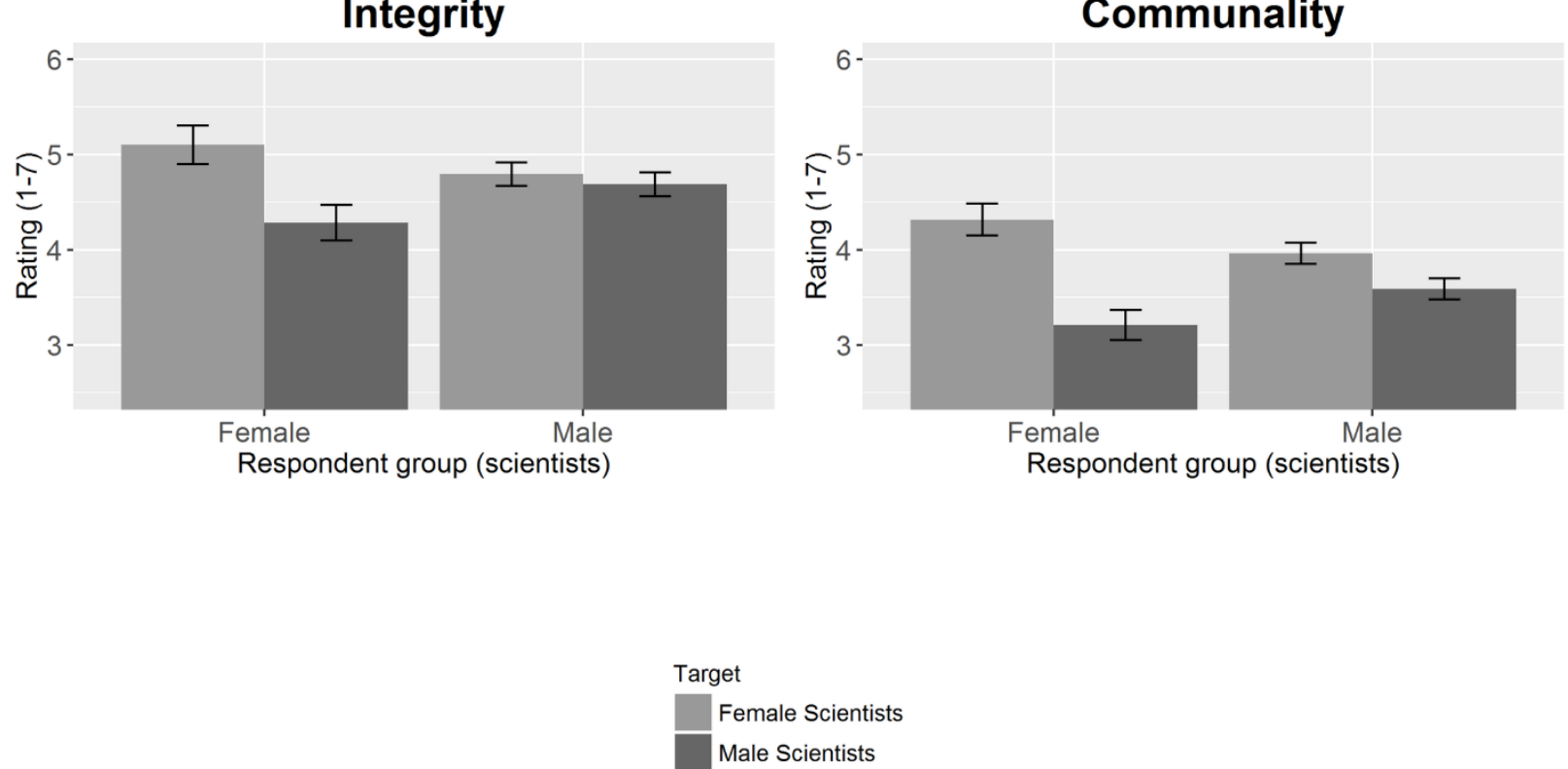

Note. The error bars represent $95 \%$ confidence intervals. 


\section{Discussion of Study 4}

Although there are no empirical data on actual gender differences in scientific traits or behavior (except for a study showing that relatively more male scientists than female scientists get caught for scientific misconduct (Fang, Bennett, \& Casadevall, 2013), Study 4 shows that female scientists are generally believed to exhibit higher levels of the scientific traits than male scientists. This contrasts with lay people's stereotypical image of the scientist being male. At the same time, we found interactions between the respondent groups and the targets that could be explained in part by in-group biases among both male and female scientists. While women perceived a larger difference between female and male scientists than men did, we cannot rule out that in-group bias led male scientists to rate female scientists lower on the scientific traits than women themselves did.

The finding that women tended to perceive larger differences between male and female scientists in terms of scientific traits might be explained by the fact that in most countries, universities are still male dominated (Shen, 2013). As minority group members, women may be more aware of inequalities and make an effort to have their in-group evaluated positively (Tajfel, 1981). In addition, minority group members tend to identify more strongly with their in-group than majority group members, and stronger group identification is associated with stronger ingroup bias (Tajfel \& Turner, 1986; Turner et al., 1987). Strikingly, research on intragroup and intergroup perception among male and female academics in a natural setting yielded results very similar to ours: in evaluations of qualities of male and female scientists in an environment where female scientists were clearly a minority, female scientists demonstrated clear in-group favoritism, while male scientists did not (Brown \& Smith, 1989). 
Even though respondents were intentionally randomly assigned to rate either male or female scientists to prevent them from explicitly comparing the two groups, in this particularly study the implicit comparison was of course obvious. As academic environments are considered rather liberal and progressive, social desirability may have played a significant role in respondents' answers. E-mails to the researchers following participation from male participants in particular indicated that the study topic was quite sensitive.

While this study was designed to test scientists' in-group bias and stereotyping, the unexpected results warrant further investigation of gender differences in scientists' perceptions of colleagues, of the sensitivity of the topic, and of actual gender differences in the scientific traits. The results also advocate taking gender into account in future studies comparing lay people's and scientists' perceptions of scientists.

\section{General Discussion}

Our results indicate strong belief among both lay people and scientists in the storybook image of the scientist as someone who is relatively objective, rational, open-minded, intelligent, honest, and communal. However, while the stereotypical image predicts that older, male scientists would be believed to fit the storybook image best, our results suggest that scientists believe that older, female scientists fit the image best. In addition, our research suggests that scientists are not immune to the human tendency to believe that members of one's own social group are less fallible than members of other groups.

The extent to which our results generalize outside our samples may be limited by selection bias among scientist respondents. The method we used to recruit scientists yielded a high number of respondents, but the overall response rate was low (around 11\%). However, our experimental designs in which participants were randomly assigned to different conditions 
should largely cancel out the potential effects of selection bias occurring through the possibility that scientists who were more interested in the topic of our study were more likely to agree to participate than scientists who were less interested in the topic. With respect to the generalizability of our samples of highly-educated Americans, we cannot exclude the possibility that although the survey panel provider Qualtrics assures representativeness of the American (highly-educated) population, people who sign up to be paid survey panel members may differ in a number of aspects from people who do not sign up to be paid survey panel members.

Our findings are particularly interesting in the context of current discussions on policy and practices aimed at reducing adverse effects of human fallibility in science. In recent years, mounting retractions due to scientific misconduct and error (Zimmer, 2012) and increasing doubts about the reproducibility of findings in many scientific fields (Ioannidis, 2005, 2012; Open Science Collaboration, 2015) have evoked numerous proposals for methods to help us stop 'fooling ourselves' (Nuzzo, 2015): new ways to reduce error, bias, and dishonesty in science. Examples include initiatives that promote transparency in the research process, publication and peer review (Nosek et al., 2015; Nosek \& Bar-Anan, 2012), pre-registration of hypotheses and data analysis plans (C. D. Chambers \& Munafo, 2013; de Groot, 1956/2014; Nosek \& Lakens, 2015; Nosek, Spies, \& Motyl, 2012; Wagenmakers, Wetzels, Borsboom, van der Maas, \& Kievit, 2012), collaboration on statistical analysis (Veldkamp, Nuijten, Dominguez-Alvarez, van Assen, \& Wicherts, 2014; Wicherts, 2011), blind data analysis (MacCoun \& Perlmutter, 2015) reforms in incentive structures (C. D. Chambers, 2015; Nosek et al., 2012), training in research integrity (Steneck, 2013), and modifications of reward systems (Ioannidis, 2014). However, the question that arises from our results is then: are scientists willing to adopt these practices if they believe that the typical scientist is mostly immune to human fallibility? Do they deem these 
initiatives necessary? And if they do deem them necessary, do they deem them necessary for themselves, or only for other (groups of) scientists?

We found that scientists may be prone to in-group bias. Here, social grouping was only made salient in terms of professional level and gender, but in real academic settings, social grouping can occur at more levels and in different ways. Scientists may categorize themselves as members of a research group, a faculty department, a faculty, an institution, a scientific field, a certain paradigm, and so on. If scientists are indeed prone to in-group biases, they may recognize that scientists are human, but still believe that scientists outside their group are more fallible than scientists within their group, and that new research policies aimed to counter human fallibilities need not focus to scientists like themselves.

The remarkable finding that established scientists believe that early-career scientists fit the storybook image of the scientist less well than $\mathrm{PhD}$ students may be related to a perceived relationship between publication pressure and use of questionable research practices (QRPs) or academic misbehavior. Early- and mid-career scientists have expressed concerns that competition and publication pressures negatively affect how science is done (Anderson, Ronning, et al., 2007), and academic age has been found to be negatively correlated with experienced publication pressure (Tijdink et al., 2013). This may lead established scientists to believe that early-career scientists are more likely to engage in QRPs (and thus fit the storybook image less well) than $\mathrm{PhD}$ students and established scientists, but studies comparing selfadmitted usage of QRPs and misbehavior between scientists of different career-stages have yielded mixed results. Some studies found that younger scientists are more likely to admit to undesirable scientific behavior (Anderson, Martinson, et al., 2007; Tijdink et al., 2014), while other studies found that older scientists are more likely to admit to this kind of behavior 
(Martinson, Anderson, Crain, \& De Vries, 2006; Martinson, Anderson, \& de Vries, 2005). Another explanation might be sought in the idea that Ph.D. students represent potential rather than practice, making it easier to imagine them as matching the ideal.

Just like any other professional endeavor involving human beings, science is prone to human error and bias. As long as we lack objective data on higher levels of objectivity, rationality, open-mindedness, intelligence, integrity or communality among scientists, the scientific community would benefit from acknowledging the human fallibility of scientists by encouraging or even implementing measures that reduce the effect of human factors. Not only scientists themselves, but science policy makers, science funders, academic institutes, and scientific publishers should all actively strive together for a 'scientific utopia' (Nosek \& BarAnan, 2012; Nosek et al., 2012): a transparent, reproducible science system in which there is room for correction of error. Institutes like the Center of Open Science (https://cos.io/) are working hard to create user-friendly platforms such as the Open Science Framework (https://osf.io/) that enable scientists to manage their entire research cycle practicing transparency, open collaboration, proper documenting, archiving and sharing of research materials, data, and analysis scripts, and to benefit in other ways from open science (McKiernan et al., 2016) [49]. Peer-reviewed study pre-registration, as offered and encouraged by the Center for Open Science's Pre-registration Challenge (see https://cos.io/prereg/), reduces 'researcher degrees of freedom' (Simmons, Nelson, \& Simonsohn, 2011) and helps scientists to avoid falling prey to human biases such as confirmation bias and hindsight bias. It's time to step off our pedestal, accept our humanness and collaborate to create an open research culture that acknowledges, but at the same time addresses, our fallibility. 


\section{References}

Anderson, M. S., Martinson, B. C., \& De Vries, R. (2007). Normative dissonance in science: Results from a national survey of U.S. scientists. Journal of Empirical Research on Human Research Ethics, 2(4):3-14.

Anderson, M. S., Ronning, E. A., De Vries, R., \& Martinson, B. C. (2007). The perverse effects of competition on scientists' work and relationships. Science and Engineering Ethics, 13(4):437-461.

Basalla, G. (1976). Pop science: the depiction of science in popular culture. In G. Holton \& W. Blanpied (Eds.), Science and its public. Dordrecht, the Netherlands: D. Reidel.

Beardslee, D. C., \& O'dowd, D. D. (1961). The college-student image of the scientist. Science, 133(3457):997-1001.

Bettencourt, B., Charlton, K., Dorr, N., \& Hume, D. L. (2001). Status differences and in-group bias: a meta-analytic examination of the effects of status stability, status legitimacy, and group permeability. Psychological bulletin, 127(4):520.

Brown, R., \& Smith, A. (1989). Perceptions of and by minority groups: The case of women in academia. European Journal of Social Psychology, 19(1):61-75.

Ceci, S. J., \& Williams, W. M. (2011). Understanding current causes of women's underrepresentation in science. Proceedings of the National Academy of Sciences, 108(8):3157-3162.

Chambers, C. D. (2015). Ten reasons why journals must review manuscripts before results are known. Addiction, 110(1):10-11.

Chambers, C. D., \& Munafo, M. R. (2013). Trust in science would be improved by study pre-registration. The Guardian. Retrieved from https://www.theguardian.com/science/blog/2013/jun/05/trust-inscience-study-pre-registration

Chambers, D. W. (1983). Stereotypic images of the scientist: The Draw-a-Scientist Test. Science Education, 67(2):255-265.

Character traits: Scientific virtue. (2016). Nature, 532(7597):139.

Cress, C. M., \& Hart, J. (2009). Playing soccer on the football field: The persistence of gender inequities for women faculty. Equity \& Excellence in Education, 42(4):473-488.

de Groot, A. D. (1956/2014). The meaning of "significance" for different types of research [translated and annotated by Eric-Jan Wagenmakers, Denny Borsboom, Josine Verhagen, Rogier Kievit, Marjan Bakker, Angelique Cramer, Dora Matzke, Don Mellenbergh, and Han L. J. van der Maas]. 1969. Acta Psychologica, 148:188-194.

Fanelli, D. (2009). How many scientists fabricate and falsify research? A systematic review and metaanalysis of survey data. PloS one, 4:e5738.

Fang, F. C., Bennett, J. W., \& Casadevall, A. (2013). Males are overrepresented among life science researchers committing scientific misconduct. MBio, 4(1):e00640-00612.

Feist, G. J. (1998). Psychology of Science as a New Subdiscipline in Psychology. Current Directions in Psychological Science, 20(5):330-334.

Fort, D. C., \& Varney, H. L. (1989). How students see scientists: Mostly male, mostly white, and mostly benevolent. Science and Children, 26(8):8-13.

Gauchat, G. (2012). Politicization of science in the public sphere a study of public trust in the United States, 1974 to 2010. American Sociological Review, 77(2):167-187.

Hassard, J. (1990). Science experiences: Cooperative learning and the teaching of science. AddisonWesley.

loannidis, J. P. A. (2005). Why most published research findings are false. Plos Medicine, 2(8):e124.

loannidis, J. P. A. (2012). Why science is not necessarily self-correcting. Perspectives on Psychological Science, 7(6):645-654.

loannidis, J. P. A. (2014). How to make more published research true. PLoS Med, 11(10):e1001747.

Ipsos MORI. (2014). Public attitudes to science 2014. Retrieved from London: https://www.ipsosmori.com/Assets/Docs/Polls/pas-2014-main-report.pdf

MacCoun, R., \& Perlmutter, S. (2015). Blind analysis: Hide results to seek the truth. Nature, 526(7572):187-189. 
Mahoney, M. J. (1976). Scientist as Subject: The Psychological Imperative. Cambridge, MA, US: Ballinger Publishing Company.

Mahoney, M. J. (1979). Psychology of the Scientist - Evaluative Review. Social Studies of Science, 9(3):349-375.

Mahoney, M. J., \& DeMonbreun, B. G. (1977). Psychology of the scientist: An analysis of probem-solving bias. Cognitive Therapy and Research, 1:229-238.

Martinson, B. C., Anderson, M. S., Crain, A. L., \& De Vries, R. (2006). Scientists' perceptions of organizational justice and self-reported misbehaviors. Journal of Empirical Research on Human Research Ethics, 1(1):51-66.

Martinson, B. C., Anderson, M. S., \& de Vries, R. (2005). Scientists behaving badly. Nature, 435(7043):737-738.

McKiernan, E. C., Bourne, P. E., Brown, C. T., Buck, S., Kenall, A., Lin, J., . . Soderberg, C. K. (2016). How open science helps researchers succeed. eLife, 5:e16800.

Mead, M., \& Metraux, R. (1973). Image of the scientist among high-school students a pilot study. Science as a Carreer Choice: Theoretical and Empirical Studies: Theoretical and Empirical Studies:314.

Merton, R. K. (1942). A Note on Science and Democracy. Journal of Legal and Political Sociology, 1:115.

Miller, D. I., Eagly, A. H., \& Linn, M. C. (2014). Women's Representation in Science Predicts National Gender-Science Stereotypes: Evidence From 66 Nations. Journal of Educational Psychology, 107(3):631-644.

Mitroff, I. I. (1974). The subjective side of science. A philosophical inquiry into the psychology of the Apollo moon scientists. Amsterdam, The Netherlands: Elsevier Scientific Publishing Company.

Newton, D. P., \& Newton, L. D. (1992). Young children's perceptions of science and the scientist. International Journal of Science Education, 14(3):331-348.

Nobelprize.org. (2014). Nobel Prizes and Laureates. Retrieved from http://www.nobelprize.org/nobel prizes/lists/all/

Nosek, B. A., Alter, G., Banks, G., Borsboom, D., Bowman, S., Breckler, S., . . Christensen, G. (2015). Promoting an open research culture: author guidelines for journals could help to promote transparency, openness, and reproducibility. Science (New York, NY), 348(6242):1422.

Nosek, B. A., \& Bar-Anan, Y. (2012). Scientific Utopia: I. Opening Scientific Communication. Psychological Inquiry, 23(3):217-243.

Nosek, B. A., \& Lakens, D. (2015). Registered reports. Social Psychology, 45:137-141.

Nosek, B. A., Spies, J., \& Motyl, M. (2012). Scientific Utopia: II - Restructuring Incentives and Practices to Promote Truth Over Publishability. Perspectives on Psychological Science, 7:615-631.

Nuzzo, R. (2015). How scientists fool themselves-and how they can stop. Nature, 526(7572):182-185.

ó Maoldomhnaigh, M., \& Hunt, Á. (1988). Some factors affecting the image of the scientist drawn by older primary school pupils. Research in Science \& Technological Education, 6(2):159-166.

Open Science Collaboration. (2015). Estimating the reproducibility of psychological science. Science, 349(6251):aac4716.

Qualtrics. (2014). Qualtrics. Provo, Utah, USA.

Rosenthal, R. (1966). Experimenter effects in behavioral research. New York: Appleton-Century-Crofts.

Shamoo, A. E., \& Resnik, D. B. (2015). Responsible conduct of research. (3rd ed.). New York: Oxford University Press.

Shen, H. (2013). Mind the gender gap. Nature, 495(7439):22-24.

Simmons, J. P., Nelson, L. D., \& Simonsohn, U. (2011). False-positive psychology: Undisclosed flexibility in data collection and analysis allows presenting anything as significant. Psychological Science, 22:1359-1366

Smith, T., \& Son, J. (2013). General Social Survey 2012 final report: Trends in public attitudes about confidence in institutions. NORC at the University of Chicago, Chicago, IL.

Steneck, N. H. (2013). Global research integrity training. Science, 340(6132):552-553.

Sugimoto, C. R. (2013). Global gender disparities in science. Nature, 504(7479):211-213.

Tajfel, H. (1981). Human groups and social categories: Studies in social psychology. Cambridge, England: Cambridge University Press.

Tajfel, H., \& Turner, J. C. (1986). The social identity theory of intergroup behavior. In S. Worchel \& W. Austin (Eds.), Psychology of intergroup relations (pp. 7-24). Chicago: Nelson-Hall.

Thomson Reuters. (2014). Web of Science ${ }^{\mathrm{TM}}$. Retrieved from https://webofknowledge.com 
Tijdink, J. K., Verbeke, R., \& Smulders, Y. M. (2014). Publication pressure and scientific misconduct in medical scientists. Journal of Empirical Research on Human Research Ethics:1-8.

Tijdink, J. K., Vergouwen, A. C., \& Smulders, Y. M. (2013). Publication pressure and burn out among Dutch medical professors: a nationwide survey. PloS one, 8(9):e73381.

Turner, J. C., Hogg, M. A., Oakes, P. J., Reicher, S. D., \& Wetherell, M. S. (1987). Rediscovering the social group: A self-categorization theory. Oxford: Blackwell.

Veldkamp, C. L. S., Nuijten, M. B., Dominguez-Alvarez, L., van Assen, M. A. L. M., \& Wicherts, J. M. (2014). Statistical reporting errors and collaboration on statistical analyses in psychological science. PloS one, 9(12):e114876.

Wagenmakers, E. J., Wetzels, R., Borsboom, D., van der Maas, H. L. J., \& Kievit, R. A. (2012). An agenda for purely confirmatory research. Perspectives on Psychological Science, 7:632-638.

Watson, D. L. (1938). Scientists Are Human. London: Watts.

West, J. D., Jacquet, J., King, M. M., Correll, S. J., \& Bergstrom, C. T. (2013). The role of gender in scholarly authorship. PloS one, 8(7):e66212.

Wicherts, J. M. (2011). Psychology must learn a lesson from fraud case. Nature, 480:7.

Williams, W. M., \& Ceci, S. J. (2015). National hiring experiments reveal 2:1 faculty preference for women on STEM tenure track. Proceedings of the National Academy of Sciences, 112(17):5360-5365.

Zimmer, C. (2012). A sharp rise in retractions prompts calls for reform. The New York Times. 


\section{Supplementary Materials}

\section{Statistical analysis and sample size determination}

\section{Study 1}

We planned to conduct a total of six ANOVAs (one for each ideal scientist feature) and to therefore use a Bonferroni-corrected family-wise alpha of 0.0083333 in each analysis. A priori power computations* yielded a required total sample size of 531 respondents $(n=133$ per group) to obtain a power of .80 to detect a small to medium effect $(f=.175)$. To be on the safe side, we aimed for 150 people per condition.

\section{Study 2}

We planned to conduct two different sets of analyses: one where we compared the pooled means of the non-scientist professions to the means of the scientist profession $(2 \times 2$ mixed design), and one where we compared the means of all different professions. We decided to only carry out the former set of analyses, but to include graphs with the means for the separate professions in the supplemental materials. The reasons for this decision were that the first set of analyses would yield more informative results with respect to our research question, and that the second set of analyses would have required a very large number of contrasted to be tested while these contrasts were not meaningful with respect to our research question itself. The nine non-scientists professions together formed a reliable scale on each of the six characteristics (Chonbach's alphas ranging from .81 to .88, see Table S3), providing support for the assumption that these professions together measure the construct 'highlyeducated professions'. With our Bonferroni-corrected alpha of 0.0083333 , we needed $124^{*}$ respondents ( $\mathrm{n}=62$ per group) to obtain a power of .80 to detect a small to moderate effect $(f=.175)$. To be on the safe side, we aimed for 75 participants per group. 


\section{Study 3}

We planned to conduct a total of six ANOVAs (one for each ideal scientist feature) and to therefore use a Bonferroni-corrected family-wise alpha of 0.0083333 in each analysis. A priori power computations* yielded a required total sample size of 762 respondents $(n=85$ per group) to obtain a power of .80 to detect a small to medium effect ( $f=.175)$.

\section{Study 4}

We planned to conduct a total of six ANOVAs (one for each ideal scientist feature) and to therefore use a Bonferroni-corrected family-wise alpha of 0.0083333 in each analysis. A priori power computations* yielded a required total sample size of 531 respondents $(n=133$ per group) to obtain a power of .80 to detect a small to medium effect $(f=.175)$.

\section{Study registration and outlier handling}

We registered our studies at the Open Science Framework. The registered studies are described in this article in the following order: 'Study A' (= Study 1), 'Study D' (= Study 2), 'Study B' (= Study 3), 'Study C' (= Study 4). The registration of this series of studies can be found through https://osf.io/z3xt6/.

In line with Bakker and Wicherts [1] and Tukey [2] we regarded data-points that lie 2 Inter Quartile Ranges (IQR) outside the lower and upper quartiles as outliers. The scripts provided on the Open Science Framework can easily be adapted to conduct the analyses without the removal of any outliers or the removal of outliers that lie 1.5 Inter Quartile Ranges (IQR) outside the lower and upper quartiles.

\footnotetext{
* Power analysis was carried out in $\mathrm{G}^{*}$ Power 1.3.6;
} 


\section{References}

1. Bakker M, Wicherts JM. Outlier removal, sum scores, and the inflation of the type I error rate in independent samples t tests: The power of alternatives and recommendations. Psychological methods. 2014;19(3):409.

2. Tukey JW. Exploratory data analysis. Reading, MA: Addison-Wesley; 1977. 


\section{Supplementary figures}

Fig. S1

Attributions of Objectivity, Rationality, Open-mindedness, Intelligence, Integrity, and Communality to the typical highly-educated person versus the typical scientist by world part.
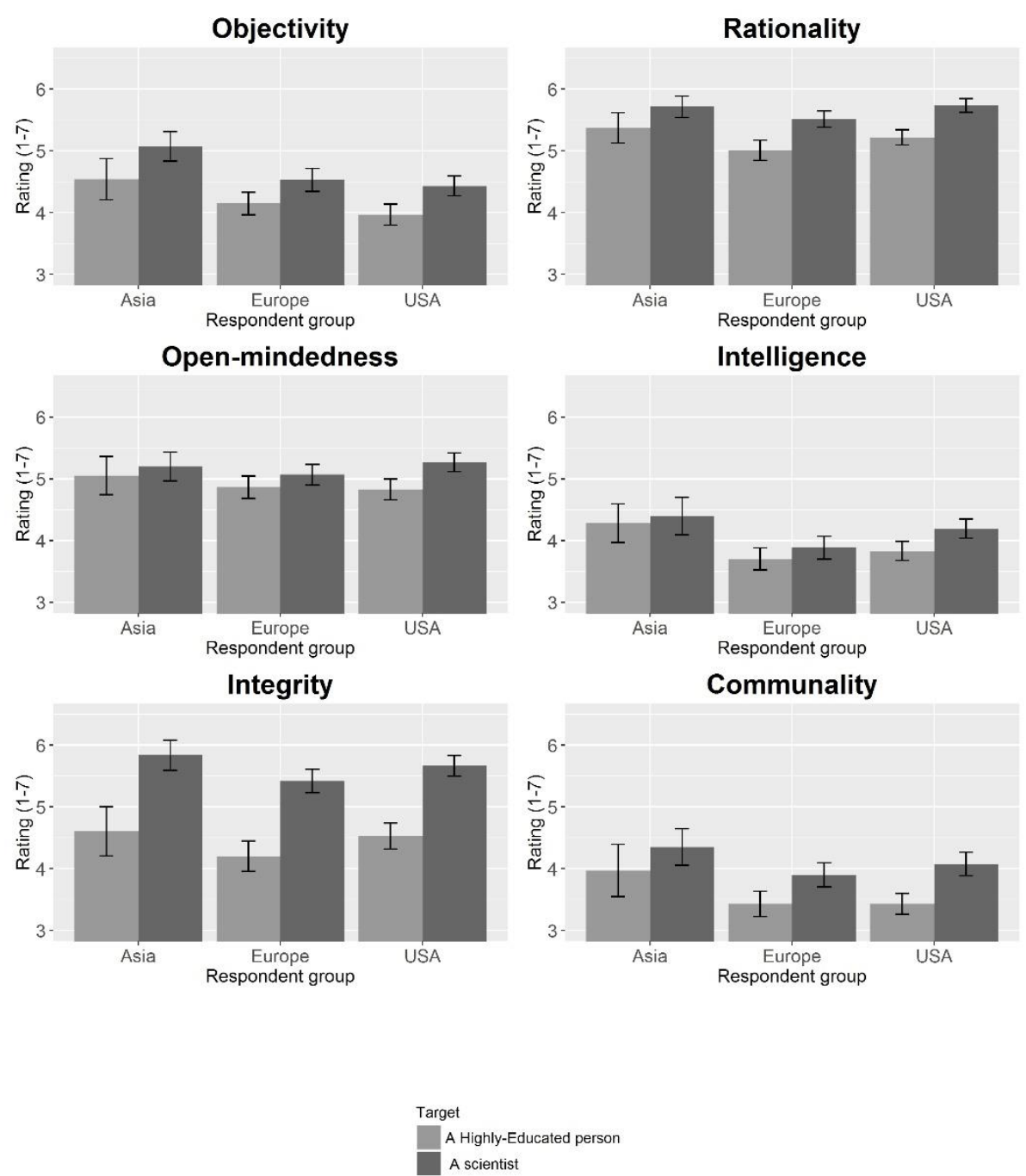

Note. Results are presented by respondent group: Asian scientists, European scientists, and American scientists. 
Fig. S2

Attributions of Objectivity, Rationality, Open-mindedness, Intelligence, Integrity, and Communality to people with various professions.
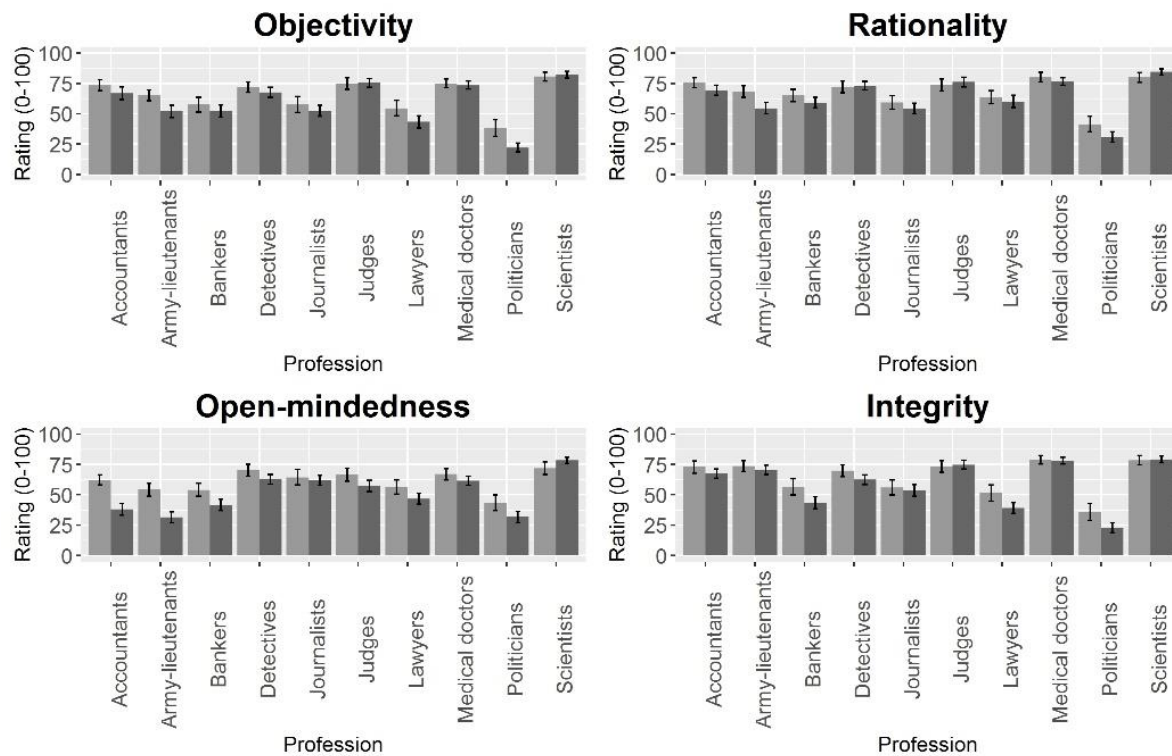

Intelligence

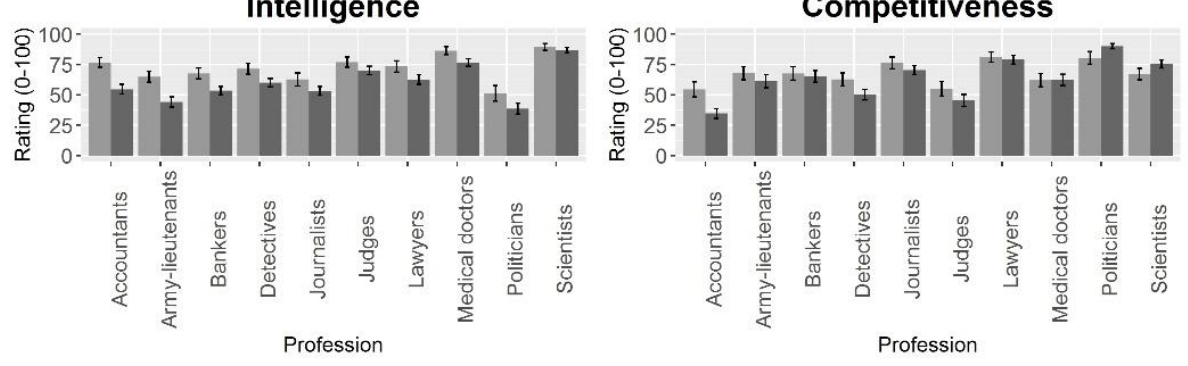

Respondent group

Educated

Scientists

Note. Results are presented by respondent group. 
Fig. S3

Attributions of Objectivity, Rationality, Open-mindedness, Intelligence, Integrity, and Communality to people with highly-educated profession versus people with the profession of scientist by world part.
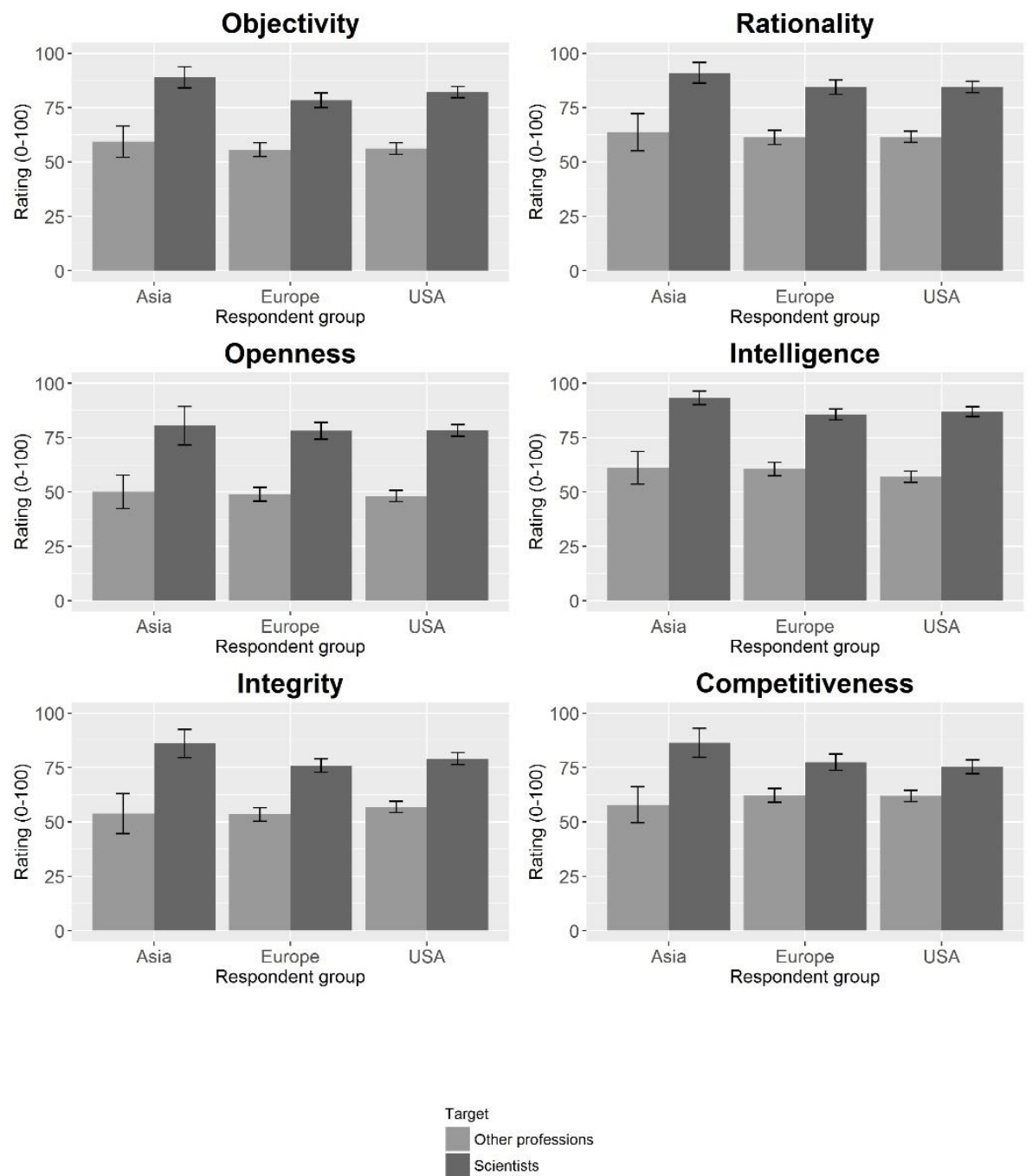

Note. Results are presented by respondent group: Asian scientists, European scientists, and American scientists. 


\section{Supplementary tables}

Table S1.

Sample details Study 1.

\begin{tabular}{|c|c|c|c|c|c|c|c|}
\hline Respondent group & $\mathrm{N}$ & $\begin{array}{l}\text { Mean Age } \\
\text { (years) }\end{array}$ & $\begin{array}{l}\begin{array}{l}\text { SD Age } \\
\text { (years) }\end{array} \\
\text { (y) }\end{array}$ & $\begin{array}{l}\text { Range Age } \\
\text { (years) }\end{array}$ & $\begin{array}{l}\text { Female } \\
(\%)\end{array}$ & $\begin{array}{l}\text { Response rate } \\
(\%)\end{array}$ & $\begin{array}{l}\text { Response rate after cleaning } \\
(\%)\end{array}$ \\
\hline American Educated & 312 & 49.2 & 13.8 & $23-84$ & 46 & $100^{*}$ & 99.37 \\
\hline American Scientists & 331 & 49.0 & 11.4 & $26-77$ & 34 & $* *$ & $* *$ \\
\hline Asian Scientists & 117 & 41.8 & 9.3 & $27-66$ & 17 & $* *$ & ** \\
\hline European Scientists & 304 & 43.6 & 10.5 & $26-75$ & 29 & $* *$ & $* *$ \\
\hline Total Scientists & 752 & & & & & 10.58 & 8.50 \\
\hline Total & 1064 & & & & & & \\
\hline Nobel Prize Laureates*** & 34 & 75.3 & 12.7 & $45-93$ & 0 & 18.95 & 17.89 \\
\hline
\end{tabular}

Note. *Qualtrics sample: paid survey panel members. **response rates cannot be computed for the world parts separately because we did not know scientists' location beforehand. The response rate is based on the total number of responses from scientists from all over the world, divided by the total number of e-mails sent to scientists from all over the world (for details see https://osf.io/3nepx/). Nobel Prize Laureates were not included in the analyses. 
Table S2.

Scale reliabilities Study 1.

\begin{tabular}{lll}
\hline Scale & $\begin{array}{l}\text { Cronbach's } \\
\text { alpha }\end{array}$ & $95 \% \mathrm{CI}$ \\
\hline Objectivity & .73 & $.66 ; .81$ \\
Rationality & .76 & $.68 ; .83$ \\
Open-mindedness & .77 & $.70 ; .85$ \\
Intelligence & .73 & $.65 ; .81$ \\
Integrity & .87 & $.81 ; .93$ \\
Communality & .79 & $.72 ; .86$ \\
\hline
\end{tabular}

Note. Based on the data of the American Educated and American scientist respondents only. $95 \% \mathrm{CI}=95 \%$ confidence interval. 


\section{Table S3.}

Correlation tables Study 1: correlations between the characteristics of the ideal scientist, by Target.

\begin{tabular}{|c|c|c|c|c|c|c|}
\hline \multicolumn{7}{|c|}{ A highly-educated person } \\
\hline Feature & 1 & 2 & 3 & 4 & 5 & 6 \\
\hline 1. Objectivity & 1 & & & & & \\
\hline 2. Rationality & $.57 * * *$ & 1 & & & & \\
\hline 3. Open-mindedness & $.70 * * *$ & $.62 * * *$ & 1 & & & \\
\hline 4. Intelligence & $.41 * * *$ & $.40 * * *$ & $.34 * * *$ & 1 & & \\
\hline 5. Integrity & $.63^{* * * *}$ & $.52 * * *$ & $.60^{* * * *}$ & $.40 * * *$ & 1 & \\
\hline 6. Communality & $.67 * * *$ & $.42 * * *$ & $.56^{* * * *}$ & $.42 * * *$ & $.68 * * *$ & 1 \\
\hline \multicolumn{7}{|l|}{ A scientist } \\
\hline 1. Objectivity & 1 & & & & & \\
\hline 2. Rationality & $.50 * * *$ & 1 & & & & \\
\hline 3. Open-mindedness & $.67 * * *$ & $.60 * * *$ & 1 & & & \\
\hline 4. Intelligence & $.30 * * *$ & $.27 * * *$ & $.23 * * *$ & 1 & & \\
\hline 5. Integrity & $.57 * * *$ & $.54 * * *$ & $.68^{* * * *}$ & .10 & 1 & \\
\hline 6. Communality & $.69 * * *$ & $.43^{* * * *}$ & $.63^{* * * *}$ & $.27 * * *$ & $.61 * * *$ & 1 \\
\hline \multicolumn{7}{|l|}{ Overall } \\
\hline 1. Objectivity & 1 & & & & & \\
\hline 2. Rationality & $.56 * * *$ & 1 & & & & \\
\hline 3. Open-mindedness & $.70^{* * * *}$ & $.62 * * *$ & 1 & & & \\
\hline 4. Intelligence & $.39 * * *$ & $.38 * * *$ & $.31 * * *$ & 1 & & \\
\hline 5. Integrity & $.63^{* * * *}$ & $.58 * * *$ & $.64 * * *$ & $.31 * * *$ & 1 & \\
\hline 6. Communality & $.70 * * *$ & $.46 * * *$ & $.61 * * *$ & $.37 * * *$ & $.67 * * *$ & 1 \\
\hline
\end{tabular}

Note. Based on the data of the American Educated and American scientist respondents only.*significant at $\alpha=.05, * *$ significant at $\alpha=.01, * * *$ significant at $\alpha=.001$. All $p$-values are adjusted for multiple testing. 


\section{Table S4.}

Statistical analyses Study 1 .

\begin{tabular}{|c|c|c|c|c|c|c|c|c|c|c|c|c|c|c|}
\hline Feature & $\begin{array}{l}\text { Respondent } \\
\text { group }\end{array}$ & Target & $\mathrm{N}$ & Mean & SD & Interaction & $\begin{array}{l}\text { Main effect } \\
\text { Target } \\
\text { (main effects } \\
\text { only model) }\end{array}$ & $\begin{array}{l}\text { t-test main } \\
\text { effect } \\
\text { Target }\end{array}$ & $\begin{array}{l}\text { Mean } \\
\text { diff }\end{array}$ & $\begin{array}{l}\text { Cohen's d } \\
{[95 \% \mathrm{CI}]}\end{array}$ & $\begin{array}{l}\text { Main effect } \\
\text { Resp. Group } \\
\text { (main effects } \\
\text { only model) }\end{array}$ & $\begin{array}{l}\text { t-test main } \\
\text { effect Resp. } \\
\text { Group }\end{array}$ & $\begin{array}{l}\text { Mean } \\
\text { diff }\end{array}$ & $\begin{array}{l}\text { Cohen's } \\
\mathrm{d} \\
{[95 \% \mathrm{CI}]}\end{array}$ \\
\hline \multirow[t]{4}{*}{ Objectivity } & Scientists & Scientist & 165 & 4.43 & 1.05 & \multirow{4}{*}{$\begin{array}{l}\mathrm{F}(1,639)= \\
0.55 \\
\mathrm{p}=.459\end{array}$} & \multirow{4}{*}{$\begin{array}{l}\mathrm{F}(1,640)= \\
37.83 \\
\mathrm{p}<.001\end{array}$} & \multirow{4}{*}{$\begin{array}{l}\mathrm{t}(641)= \\
5.95, \\
\mathrm{p}<.001\end{array}$} & \multirow[t]{4}{*}{0.52} & \multirow{4}{*}{$\begin{array}{l}0.47 \\
{[0.31 ; 0.63]}\end{array}$} & \multirow{4}{*}{$\begin{array}{l}\mathrm{F}(1,640)= \\
34.33, \\
\mathrm{p}<.001\end{array}$} & \multirow{4}{*}{$\begin{array}{l}\mathrm{t}(641)= \\
-5.65, \\
\mathrm{p}<.001\end{array}$} & \multirow[t]{4}{*}{-0.47} & \multirow{4}{*}{$\begin{array}{l}-0.45 \\
{[-0.60 ;-0.29}\end{array}$} \\
\hline & & Educated & 166 & 3.97 & 1.09 & & & & & & & & & \\
\hline & Educated & Scientist & 153 & 4.99 & 1.14 & & & & & & & & & \\
\hline & & Educated & 159 & 4.40 & 1.04 & & & & & & & & & \\
\hline \multirow[t]{4}{*}{ Rationality } & Scientists & Scientist & 165 & 5.73 & 0.71 & \multirow{4}{*}{$\begin{array}{l}\mathrm{F}(1,639)= \\
0.26 \\
\mathrm{p}=.613\end{array}$} & \multirow{4}{*}{$\begin{array}{l}\mathrm{F}(1,640)= \\
64.68, \\
\mathrm{p}<.001\end{array}$} & \multirow{4}{*}{$\begin{array}{l}\mathrm{t}(641)= \\
8.04, \\
\mathrm{p}<.001\end{array}$} & \multirow[t]{4}{*}{0.55} & \multirow{4}{*}{$\begin{array}{l}0.63 \\
{[0.48 ; 0.79]}\end{array}$} & \multirow{4}{*}{$\begin{array}{l}\mathrm{F}(1,640)= \\
4.02, \\
\mathrm{p}=.045\end{array}$} & \multirow{4}{*}{$\begin{array}{l}\mathrm{t}(641)= \\
1.97, \\
\mathrm{p}=.049\end{array}$} & \multirow[t]{4}{*}{0.14} & \multirow{4}{*}{$\begin{array}{l}0.16 \\
{[0.00 ; 0.31]}\end{array}$} \\
\hline & & Educated & 166 & 5.22 & 0.79 & & & & & & & & & \\
\hline & Educated & Scientist & 153 & 5.63 & 0.88 & & & & & & & & & \\
\hline & & Educated & 159 & 5.05 & 1.05 & & & & & & & & & \\
\hline \multirow[t]{4}{*}{ Openness } & Scientists & Scientist & 165 & 5.27 & 0.98 & \multirow{4}{*}{$\begin{array}{l}\mathrm{F}(1,639)= \\
0.58 \\
\mathrm{p}=.445\end{array}$} & \multirow{4}{*}{$\begin{array}{l}\mathrm{F}(1,640)= \\
19.28 \\
\mathrm{p}<.001\end{array}$} & \multirow{4}{*}{$\begin{array}{l}\mathrm{t}(641)= \\
4.40, \\
\mathrm{p}<.001\end{array}$} & \multirow[t]{4}{*}{0.38} & \multirow{4}{*}{$\begin{array}{l}0.35 \\
{[0.19 ; 0.50]}\end{array}$} & \multirow{4}{*}{$\begin{array}{l}\mathrm{F}(1,640)= \\
0.89 \\
\mathrm{p}=.347\end{array}$} & \multirow{4}{*}{$\begin{array}{l}\mathrm{t}(641)= \\
0.96 \\
\mathrm{p}=.335\end{array}$} & \multirow[t]{4}{*}{0.08} & 0.08 \\
\hline & & Educated & 166 & 4.83 & 1.12 & & & & & & & & & {$[-0.08 ; 0.23]$} \\
\hline & Educated & Scientist & 153 & 5.12 & 1.23 & & & & & & & & & \\
\hline & & Educated & 159 & 4.81 & 1.00 & & & & & & & & & \\
\hline Intelligence & Scientists & Scientist & 165 & 4.19 & 1.02 & $\mathrm{~F}(1,639)=$ & $\mathrm{F}(1,640)=$ & $t(641)=$ & 0.51 & 0.44 & $\mathrm{~F}(1,640)=$ & $t(641)=$ & -0.42 & -0.36 \\
\hline & & Educated & 166 & 3.83 & 1.02 & 2.99 & 32.93 & 5.61, & & {$[0.29 ; 0.60]$} & 22.53 & -4.59 & & {$[-0.52 ;-0.21]$} \\
\hline & Educated & Scientist & 153 & 4.77 & 1.27 & $\mathrm{p}=.084$ & $\mathrm{p}<.001$ & $p<.001$ & & & $\mathrm{p}<.001$ & $\mathrm{p}<.001$ & & \\
\hline & & Educated & 159 & 4.10 & 1.19 & & & & & & & & & \\
\hline Integrity & Scientists & Scientist & 165 & 5.66 & 1.07 & $\mathrm{~F}(1,639)=$ & $\mathrm{F}(1,640)=$ & $\mathrm{t}(641)=$ & 0.98 & 0.77 & $\mathrm{~F}(1,640)=$ & $t(641)=$ & 0.31 & 0.23 \\
\hline & & Educated & 166 & 4.53 & 1.37 & 2.84 & 96.57 & 9.79 & & {$[0.61 ; 0.93]$} & 9.21 & 2.91 & & {$[0.07 ; 0.38]$} \\
\hline & Educated & Scientist & 153 & 5.19 & 1.28 & $\mathrm{p}=.092$ & $\mathrm{p}<.001$ & $\mathrm{p}<.001$ & & & $\mathrm{p}=.003$ & $\mathrm{p}=.004$ & & \\
\hline & & Educated & 159 & 4.39 & 1.29 & & & & & & & & & \\
\hline Coттипаlity & Scientists & Scientist & 165 & 4.07 & 1.23 & & $\mathrm{~F}(1,640)=$ & & 0.59 & & $\mathrm{~F}(1,640)=$ & & -0.58 & -0.47 \\
\hline & & Educated & 166 & 3.43 & 1.10 & 0.30 & 39.27 & 6.05 & & {$[0.32 ; 0.63]$} & 37.55 & -5.90 & & {$[-0.62 ;-0.31]$} \\
\hline & Educated & Scientist & 153 & 4.60 & 1.29 & $\mathrm{p}=.582$ & $\mathrm{p}<.001$ & $\mathrm{p}<.001$ & & & $\mathrm{p}<.001$ & $\mathrm{p}<.001$ & & \\
\hline & & Educated & 159 & 4.06 & 1.20 & & & & & & & & & \\
\hline
\end{tabular}

Note. Based on data of American educated and American scientist respondents only. For interactions and main effects, $\alpha=.008333$; for subsequent tests of simple effects, $\alpha=0.05$. Text in grey represents non-significant results. 
Table S5.

Sample details Study 2.

\begin{tabular}{|c|c|c|c|c|c|c|c|}
\hline Respondent group & $\mathrm{N}$ & $\begin{array}{l}\text { Mean Age } \\
\text { (years) }\end{array}$ & $\begin{array}{l}\begin{array}{l}\text { SD Age } \\
\text { (years) }\end{array} \\
\text { (y) }\end{array}$ & $\begin{array}{l}\text { Range Age } \\
\text { (years) }\end{array}$ & $\begin{array}{l}\text { Female } \\
(\%)\end{array}$ & $\begin{array}{l}\text { Response rate } \\
(\%)\end{array}$ & $\begin{array}{l}\text { Response rate after cleaning } \\
(\%)\end{array}$ \\
\hline American Educated & 75 & 46.3 & 14.7 & $22-83$ & $47 \%$ & $100 *$ & $75.70 *$ \\
\hline American Scientists & 111 & 49.9 & 12.4 & $27-85$ & $20 \%$ & $* *$ & $* *$ \\
\hline Asian Scientists & 20 & 45.5 & 12.3 & $26-69$ & $15 \%$ & $* *$ & ** \\
\hline European Scientists & 67 & 44.6 & 10.6 & $28-75$ & $25 \%$ & ** & $* *$ \\
\hline Total Scientists & 198 & & & & & 10.97 & 6.76 \\
\hline Total & 273 & & & & & & \\
\hline
\end{tabular}

Note. *Qualtrics sample: paid survey panel members. **response rates cannot be computed for the world parts separately because we did not know scientists' location beforehand. The response rate is based on the total number of responses from scientists from all over the world, divided by the total number of e-mails sent to scientists from all over the world (for details see https://osf.io/3nepx/). 


\section{Table S6.}

Scale reliabilities Study 2.

\begin{tabular}{lll}
\hline Scale & $\begin{array}{l}\text { Cronbach's } \\
\text { alpha }\end{array}$ & $95 \% \mathrm{CI}$ \\
\hline Objectivity & .81 & $.74 ; .87$ \\
Rationality & .83 & $.77 ; .89$ \\
Open-mindedness & .83 & $.77 ; .89$ \\
Intelligence & .88 & $.83 ; .93$ \\
Integrity & .84 & $.78 ; .90$ \\
Competitiveness & .81 & $.74 ; .87$ \\
\hline
\end{tabular}

Note. Based on the data of the American Educated and American scientist respondents only. $95 \% \mathrm{CI}=95 \%$ confidence interval. 


\section{Table S7.}

Correlation tables Study 2: correlations between the characteristics of the ideal scientist, by profession category.

\begin{tabular}{|c|c|c|c|c|c|c|}
\hline \multicolumn{7}{|c|}{ Highly-educated professions } \\
\hline Feature & 1 & 2 & 3 & 4 & 5 & 6 \\
\hline 1. Objectivity & 1 & & & & & \\
\hline 2. Rationality & $.73 * * *$ & 1 & & & & \\
\hline 3. Open-mindedness & $.75^{* * * *}$ & $.68^{* * * *}$ & 1 & & & \\
\hline 4. Intelligence & $.75^{* * * *}$ & $.72 * * *$ & $.74 * * *$ & 1 & & \\
\hline 5. Integrity & $.71 * * *$ & $.71^{* * * *}$ & $.68 * * *$ & $.72 * * *$ & 1 & \\
\hline 6. Communality & $.48 * * *$ & $.49^{* * * *}$ & $.49 * * *$ & $.54 * * *$ & $.38 * * *$ & 1 \\
\hline \multicolumn{7}{|l|}{ Profession of scientist } \\
\hline 1. Objectivity & 1 & & & & & \\
\hline 2. Rationality & .60 *** & 1 & & & & \\
\hline 3. Open-mindedness & $.47 * * *$ & $.39^{* * * *}$ & 1 & & & \\
\hline 4. Intelligence & $.48 * * *$ & $.47 * * *$ & $.21 *$ & 1 & & \\
\hline 5. Integrity & $.57 * * *$ & $.49^{* * * *}$ & $.33 * * *$ & $.46 * * *$ & 1 & \\
\hline 6. Communality & .10 & .12 & $.28 * * *$ & .13 & .09 & 1 \\
\hline
\end{tabular}

Note. Based on the data of the American Educated and American scientist respondents only.*significant at $\alpha=.05, * *$ significant at $\alpha=.01, * * *$ significant at $\alpha=.001$. All $p$-values are adjusted for multiple testing. 


\section{Table S8.}

Statistical analyses Study 2.

\begin{tabular}{|c|c|c|c|c|c|c|c|c|c|c|c|}
\hline Feature & $\begin{array}{l}\text { Respondent } \\
\text { group }\end{array}$ & Target & $\mathrm{N}$ & Mean & SD & Interaction & Simple effects & Mean diff. & Correlation & $\begin{array}{l}\text { Cohen's d } \\
{[95 \% \mathrm{CI}]} \\
\end{array}$ & $\begin{array}{l}\text { Diff. } \\
\text { d }\end{array}$ \\
\hline \multirow[t]{4}{*}{ Objectivity } & Scientists & Scientist & 111 & 82.14 & 14.02 & \multirow{4}{*}{$\begin{array}{l}\mathrm{t}(184)= \\
3.61, \\
\mathrm{p}<.001\end{array}$} & $\mathrm{t}(110)=18.50$, & 25.97 & .87 & 1.76 & \multirow[t]{4}{*}{0.73} \\
\hline & & Educated & 111 & 56.18 & 14.11 & & $\mathrm{p}<.001$ & & & {$[1.57 ; 1.94]$} & \\
\hline & \multirow[t]{2}{*}{ Educated } & Scientist & 75 & 80.64 & 16.05 & & $\mathrm{t}(74)=8.87$ & 17.48 & .72 & 1.02 & \\
\hline & & Educated & 75 & 63.16 & 15.22 & & $\mathrm{p}<.001$ & & & {$[0.79 ; 1.25]$} & \\
\hline \multirow[t]{4}{*}{ Rationality } & Scientists & Scientist & 111 & 84.48 & 13.77 & \multirow{4}{*}{$\begin{array}{l}\mathrm{t}(184)= \\
4.04 \\
\mathrm{p}<.001\end{array}$} & $\mathrm{t}(110)=15.80$, & 22.91 & .83 & 1.50 & \multirow[t]{4}{*}{0.71} \\
\hline & & Educated & 111 & 61.57 & 13.95 & & $\mathrm{p}<.001$ & & & {$[1.31 ; 1.69]$} & \\
\hline & \multirow[t]{2}{*}{ Educated } & Scientist & 75 & 79.89 & 16.97 & & $\mathrm{t}(74)=6.83$ & 13.30 & .62 & 0.79 & \\
\hline & & Educated & 75 & 66.60 & 14.80 & & $\mathrm{p}<.001$ & & & {$[0.56 ; 1.02]$} & \\
\hline \multirow[t]{4}{*}{ Open-mindedness } & Scientists & Scientist & 111 & 78.31 & 14.39 & \multirow{4}{*}{$\begin{array}{l}\mathrm{t}(184)= \\
6.62 \\
\mathrm{p}<.001\end{array}$} & $\mathrm{t}(110)=17.99$, & 30.17 & .86 & & \multirow[t]{4}{*}{1.08} \\
\hline & \multirow{3}{*}{ Educated } & Educated & 111 & 48.14 & 13.83 & & $\mathrm{p}<.001$ & & & {$[1.52 ; 1.90]$} & \\
\hline & & Scientist & 75 & 71.85 & 22.58 & & $\mathrm{t}(74)=5.43$, & 12.05 & .53 & 0.63 & \\
\hline & & Educated & 75 & 59.80 & 16.08 & & $\mathrm{p}<.001$ & & & {$[0.40 ; 0.86]$} & \\
\hline \multirow[t]{4}{*}{ Intelligence } & Scientists & $\begin{array}{l}\text { Scientist } \\
\end{array}$ & 111 & 86.87 & 11.83 & \multirow{4}{*}{$\begin{array}{l}\mathrm{t}(184)= \\
4.80, \\
\mathrm{p}<.001\end{array}$} & $\mathrm{t}(110)=19.82$ & 29.87 & .88 & 1.88 & \multirow[t]{4}{*}{0.45} \\
\hline & \multirow{3}{*}{ Educated } & Educated & 111 & 57.00 & 13.46 & & $\mathrm{p}<.001$ & & & {$[1.69 ; 2.07]$} & \\
\hline & & Scientist & 75 & 89.25 & 12.05 & & $\mathrm{t}(74)=12.43$ & 19.17 & .82 & 1.44 & \\
\hline & & Educated & 75 & 70.08 & 13.97 & & $\mathrm{p}<.001$ & & & {$[1.21 ; 1.67]$} & \\
\hline \multirow[t]{4}{*}{ Integrity } & Scientists & Scientist & 111 & 79.09 & 14.73 & \multirow{4}{*}{$\begin{array}{l}\mathrm{t}(184)= \\
2.89 \\
\mathrm{p}=.004\end{array}$} & $\mathrm{t}(110)=15.86$, & 22.18 & .83 & 1.51 & \multirow[t]{4}{*}{0.64} \\
\hline & \multirow{3}{*}{ Educated } & Educated & 111 & 56.91 & 13.46 & & $\mathrm{p}<.001$ & & & {$[1.32 ; 1.69]$} & \\
\hline & & Scientist & 75 & 78.44 & 16.21 & & $\mathrm{t}(74)=7.53$ & 15.29 & .66 & 0.87 & \\
\hline & & Educated & 75 & 63.15 & 17.28 & & $\mathrm{p}<.001$ & & & {$[0.64 ; 1.10]$} & \\
\hline \multirow{4}{*}{ Competitiveness } & Scientists & Scientist & 111 & 75.39 & 16.85 & \multirow{4}{*}{$\begin{array}{l}\mathrm{t}(184)= \\
5.44, \\
\mathrm{p}<.001\end{array}$} & $\mathrm{t}(110)=7.87$ & 13.4 & .60 & 0.75 & \multirow[t]{4}{*}{0.77} \\
\hline & & Educated & 111 & 61.99 & 13.78 & & $\mathrm{p}<.001$ & & & {$[0.56 ; 0.93]$} & \\
\hline & \multirow[t]{2}{*}{ Educated } & Scientist & 75 & 67.08 & 20.74 & & $\mathrm{t}(74)=-.22$ & -0.40 & .03 & -0.03 & \\
\hline & & Educated & 75 & 67.48 & 15.47 & & $\mathrm{p}=.82$ & & & {$[-0.26 ; 0.20]$} & \\
\hline
\end{tabular}

Note. Based on data of American educated and American scientist respondents only. For interactions and main effects, $\alpha=.008333$; for subsequent tests of simple effects, $\alpha=0.05$. Text in grey represents non-significant results. 


\section{Table S9.}

Sample details Study 3.

\begin{tabular}{llllllll}
\hline Respondent group & $\mathrm{N}$ & $\begin{array}{l}\text { Mean Age } \\
\text { (years) }\end{array}$ & $\begin{array}{l}\text { SD Age } \\
\text { (years) }\end{array}$ & $\begin{array}{l}\text { Range Age } \\
\text { (years) }\end{array}$ & $\begin{array}{l}\text { Female } \\
(\%)\end{array}$ & $\begin{array}{l}\text { Response rate } \\
(\%)\end{array}$ & $\begin{array}{l}\text { Response rate after cleaning } \\
(\%)\end{array}$ \\
\hline Early-career scientists & 515 & 35.2 & 5.8 & $26-94^{1}$ & $33 \%$ & $*$ & $*$ \\
Established scientists & 903 & 51.9 & 9.2 & $35-90$ & $22 \%$ & $*$ & $*$ \\
\hline Total & 1418 & & & & & 10.55 & 5.97 \\
\hline
\end{tabular}

Note. ${ }^{1}$ Probably erroneous maximum age: one person selected the first answer option on the list, which translates to age $=94$. *Response rates cannot be computed for the two respondent groups separately because we did not know scientists' career level beforehand. The response rate is based on the total number of responses divided by the total number of e-mails sent (for details see https://osf.io/3nepx/). 
Table S10.

Scale reliabilities Study 3.

\begin{tabular}{lll}
\hline Scale & $\begin{array}{l}\text { Cronbach's } \\
\text { alpha }\end{array}$ & $95 \% \mathrm{CI}$ \\
\hline Objectivity & .63 & $.57 ; .69$ \\
Rationality & .74 & $.69 ; .79$ \\
Open-mindedness & .67 & $.61 ; .73$ \\
Intelligence & .70 & $.65 ; .75$ \\
Integrity & .82 & $.77 ; .86$ \\
Communality & .63 & $.57 ; .69$ \\
\hline
\end{tabular}

Note. $95 \% \mathrm{CI}=95 \%$ confidence interval. 
Table S11.

Correlation tables Study 3: correlations between the characteristics of the ideal scientist, by respondent group.

\begin{tabular}{|c|c|c|c|c|c|c|}
\hline \multicolumn{7}{|l|}{ Early-career scientists } \\
\hline Feature & 1 & 2 & 3 & 4 & 5 & 6 \\
\hline 1. Objectivity & 1 & & & & & \\
\hline 2. Rationality & $.52 * * *$ & 1 & & & & \\
\hline 3. Open-mindedness & $.61 * * *$ & $.49 * * *$ & 1 & & & \\
\hline 4. Intelligence & $.24 * * *$ & $.31^{* * * *}$ & $.16^{* * * *}$ & 1 & & \\
\hline 5. Integrity & $.57 * * *$ & $.53 * * *$ & $.58 * * *$ & $.24 * * *$ & 1 & \\
\hline 6. Communality & $.54 * * *$ & $.29 * * *$ & $.46^{* * * *}$ & $.18 * * *$ & $.55^{* * * *}$ & 1 \\
\hline \multicolumn{7}{|l|}{ Established scientists } \\
\hline 1. Objectivity & 1 & & & & & \\
\hline 2. Rationality & $.52 * * *$ & 1 & & & & \\
\hline 3. Open-mindedness & $.61 * * *$ & $.57 * * *$ & 1 & & & \\
\hline 4. Intelligence & $.35 * * *$ & $.44 * * *$ & $.29 * * *$ & 1 & & \\
\hline 5. Integrity & $.54 * * *$ & $.54 * * *$ & $.58 * * *$ & $.21 * * *$ & 1 & \\
\hline 6. Communality & $.55^{* * * *}$ & $.36 * * *$ & $.49 * * *$ & $.25 * * *$ & $.53 * * *$ & 1 \\
\hline \multicolumn{7}{|l|}{ Overall } \\
\hline 1. Objectivity & 1 & & & & & \\
\hline 2. Rationality & $.52 * * *$ & 1 & & & & \\
\hline 3. Open-mindedness & $.61 * * *$ & $.54 * * *$ & 1 & & & \\
\hline 4. Intelligence & $.32 * * *$ & $.39^{* * *}$ & $.25 * * *$ & 1 & & \\
\hline 5. Integrity & $.56 * * *$ & $.54 * * *$ & $.58 * * *$ & $.23^{* * * *}$ & 1 & \\
\hline 6. Communality & $.55 * * *$ & $.33 * * *$ & $.48 * * *$ & $.23 * * *$ & $.55 * * *$ & 1 \\
\hline
\end{tabular}

Note. *significant at $\alpha=.05, * *$ significant at $\alpha=.01, * * *$ significant at $\alpha=.001$. All $p$-values are adjusted for multiple testing. 
Table 12.

Statistical analyses Study 3.

\begin{tabular}{|c|c|c|c|c|c|c|c|c|c|c|c|}
\hline Feature & $\begin{array}{l}\text { Respondent } \\
\text { group }\end{array}$ & Target & $\mathrm{N}$ & Mean & SD & Interaction & $\begin{array}{l}\text { Simple effects: effect of Target in } \\
\text { each respondent group separately }\end{array}$ & Comparisons & t-tests & $\begin{array}{l}\text { Mean } \\
\text { diff. }\end{array}$ & $\begin{array}{l}\text { Cohen's } \\
\mathrm{D}[95 \% \mathrm{CI}] \\
\end{array}$ \\
\hline \multirow[t]{6}{*}{ Objectivity } & \multirow{3}{*}{ Early-career } & Early-career & 179 & 4.35 & 0.95 & \multirow{6}{*}{$\begin{array}{l}\mathrm{F}(2,1412) \\
=6.50 \\
\mathrm{p}=.002 \\
*\end{array}$} & \multirow{3}{*}{$\mathrm{F}(2,512)=3.83, \mathrm{p}=.022$} & Established - Early & $\mathrm{t}(344)=-0.06, \mathrm{p}=.953$ & -0.01 & $-0.01[-0.22 ; 0.21]$ \\
\hline & & Established & 167 & 4.34 & 1.20 & & & Early - PhD & $\mathrm{t}(346)=2.65, \mathrm{p}=.008$ & 0.28 & $0.28[0.07 ; 0.50]$ \\
\hline & & PhD-students & 169 & 4.07 & 0.98 & & & Established - PhD & $\mathrm{t}(334)=2.25, \mathrm{p}=.025$ & 0.27 & $0.25[0.03 ; 0.46]$ \\
\hline & \multirow[t]{3}{*}{ Established } & Early-career & 290 & 4.27 & 0.99 & & \multirow[t]{3}{*}{$\mathrm{F}(2,900)=14.45, \mathrm{p}<.001$} & Established - Early & $\mathrm{t}(604)=5.06, p<.001$ & 0.42 & $0.41[0.25 ; 0.57]$ \\
\hline & & Established & 316 & 4.70 & 1.07 & & & Early - PhD & $\mathrm{t}(585)=-1.71, \mathrm{p}=.088$ & -0.14 & $-0.17[-0.30 ; 0.02]$ \\
\hline & & PhD-students & 297 & 4.41 & 0.92 & & & Established - PhD & $\mathrm{t}(611)=3.57, \mathrm{p}<.001$ & 0.29 & $0.30[0.13 ; 0.45]$ \\
\hline \multirow[t]{6}{*}{ Rationality } & \multirow[t]{3}{*}{ Early-career } & Early-career & 179 & 5.25 & 0.92 & \multirow{6}{*}{$\begin{array}{l}\mathrm{F}(2,1412) \\
= \\
5.07 \\
\mathrm{p}=.006\end{array}$} & \multirow[t]{3}{*}{$\mathrm{F}(2,512)=21.04, \mathrm{p}<.001$} & Established - Early & $\mathrm{t}(344)=3.14, \mathrm{p}=.002$ & 0.31 & $0.34[0.12 ; 0.55]$ \\
\hline & & Established & 167 & 5.55 & 0.89 & & & Early - PhD & $\mathrm{t}(346)=3.40, \mathrm{p}<.001$ & 0.32 & $0.36[0.15 ; 0.58]$ \\
\hline & & PhD-students & 169 & 4.92 & 0.86 & & & Established - PhD & $\mathrm{t}(334)=6.59, \mathrm{p}<.001$ & 0.63 & $0.72[0.50 ; 0.94]$ \\
\hline & \multirow[t]{3}{*}{ Established } & Early-career & 290 & 5.03 & 0.99 & & \multirow[t]{3}{*}{$\mathrm{F}(2,900)=37.90, \mathrm{p}<.001$} & Established - Early & $\mathrm{t}(604)=7.92, \mathrm{p}<.001$ & 0.59 & $0.64[0.48 ; 0.81]$ \\
\hline & & Established & 316 & 5.62 & 0.84 & & & Early - PhD & $\mathrm{t}(585)=-0.66, \mathrm{p}=.509$ & -0.05 & $-0.05[-0.22 ; 0.11]$ \\
\hline & & PhD-students & 297 & 5.08 & 0.96 & & & Established - PhD & $\mathrm{t}(611)=7.39, \mathrm{p}<.001$ & 0.54 & $0.60[0.44 ; 0.76]$ \\
\hline \multirow[t]{6}{*}{ Openness } & \multirow[t]{3}{*}{ Early-career } & Early-career & 179 & 5.04 & 0.91 & \multirow{6}{*}{$\begin{array}{l}\mathrm{F}(2,1412) \\
= \\
11.53 \\
\mathrm{p}<.001\end{array}$} & \multirow[t]{3}{*}{$\mathrm{F}(2,512)=2.48, \mathrm{p}=.085$} & & & & \\
\hline & & Established & 167 & 5.03 & 1.10 & & & & & & \\
\hline & & PhD-students & 169 & 4.84 & 0.82 & & & & & & \\
\hline & \multirow[t]{3}{*}{ Established } & Early-career & 290 & 4.80 & 1.02 & & \multirow[t]{3}{*}{$\mathrm{F}(2,900)=32.22, \mathrm{p}<.001$} & Established - Early & $\mathrm{t}(604)=7.68, \mathrm{p}<.001$ & 0.62 & $0.62[0.46 ; 0.79]$ \\
\hline & & Established & 316 & 5.42 & 0.98 & & & Early - PhD & $\mathrm{t}(585)=-2.80, \mathrm{p}=.005$ & -0.22 & $-0.23[-0.49 ;-0.07]$ \\
\hline & & PhD-students & 297 & 5.02 & 0.91 & & & Established - PhD & $\mathrm{t}(611)=5.22, \mathrm{p}<.001$ & 0.40 & $0.42[0.26 ; 0.58]$ \\
\hline \multirow[t]{6}{*}{ Intelligence } & \multirow[t]{3}{*}{ Early-career } & Early-career & 179 & 3.66 & 1.04 & \multirow{6}{*}{$\begin{array}{l}F(2,1412) \\
=1.46 \\
p=.234\end{array}$} & \multirow{5}{*}{$\begin{array}{l}\text { Main effect of Respondent Group: } \\
F(1,1414)=44.08, p<.001 \\
\text { No main effect of Target: } \\
F(2,1414)=2.20, p=.111\end{array}$} & Established - Early & $t(1416)=6.70, p<.001$ & 0.43 & $0.37[0.26 ; 0.48]$ \\
\hline & & Established & 167 & 3.73 & 1.12 & & & & & & \\
\hline & & PhD-students & 169 & 3.55 & 1.09 & & & & & & \\
\hline & \multirow{3}{*}{ Established } & Early-career & 290 & 3.95 & 1.17 & & & & & & \\
\hline & & Established & 316 & 4.15 & 1.18 & & & & & & \\
\hline & & PhD-students & 297 & 4.11 & 1.15 & & (Model with main effects only) & & & & \\
\hline \multirow[t]{6}{*}{ Integrity } & \multirow[t]{3}{*}{ Early-career } & Early-career & 179 & 5.24 & 1.16 & $\mathrm{~F}(2,1412)$ & $\mathrm{F}(2,512)=3.56, \mathrm{p}=.029$ & Established - Early & $\mathrm{t}(344)=1.59, \mathrm{p}=.113$ & 0.20 & $0.17[-0.04 ; 0.38]$ \\
\hline & & Established & 167 & 5.45 & 1.22 & & & Early - PhD & $\mathrm{t}(346)=1.08, \mathrm{p}=.281$ & 0.13 & $0.12[-0.10 ; 0.33]$ \\
\hline & & PhD-students & 169 & 5.11 & 1.07 & 8.62 & & Established - PhD & $\mathrm{t}(334)=2.66, \mathrm{p}=.008$ & 0.33 & $0.29[0.07 ; 0.51]$ \\
\hline & Established & Early-career & 290 & 5.05 & 1.15 & $\mathrm{p}<.001$ & $\mathrm{~F}(2,900)=31.67, \mathrm{p}<.001$ & Established - Early & $\mathrm{t}(604)=7.49, \mathrm{p}<.001$ & 0.69 & $0.61[0.45 ; 0.77]$ \\
\hline & & Established & 316 & 5.74 & 1.12 & & & Early - PhD & $\mathrm{t}(585)=-5.27, \mathrm{p}=.001$ & -0.46 & $-0.44[-0.60 ;-0.27]$ \\
\hline & & PhD-students & 297 & 5.51 & 0.97 & & & Established - PhD & $\mathrm{t}(611)=2.70, \mathrm{p}=.007$ & 0.23 & $0.22[0.06 ; 0.38]$ \\
\hline Communality & Early-career & Early-career & 179 & 3.88 & 1.07 & $F(2,1412)$ & Main effect of Target: & Established - Early & $\mathrm{t}(928.38)=3.32, \mathrm{p}<$ & 0.25 & $0.22[0.09 ; 0.34]$ \\
\hline & & Established & 167 & 3.89 & 1.27 & & $\mathrm{~F}(2,1414)=11.17, \mathrm{p}<.001$ & & $.001 *$ & & \\
\hline & & PhD-students & 169 & 3.97 & 1.08 & 4.36, & No main effect of Resp. group: & Early - PhD & & $\begin{array}{l}-0.33 \\
\end{array}$ & $-0.32[-0.45 ;-0.20]$ \\
\hline & Established & Early-career & 290 & 3.74 & 1.03 & $\mathrm{p}=.013$ & $\mathrm{~F}(1,1414)=2.95, \mathrm{p}=.086$ & & $.001 *$ & & \\
\hline & & Established & 316 & 4.12 & 1.24 & & & Established - PhD & $\mathrm{t}(911.09)=-1.12, \mathrm{p}=$ & -0.08 & $-0.07[-0.20 ; 0.05]$ \\
\hline & & PhD-students & 297 & 4.21 & 0.93 & & (Model with main effects only) & & $.263 *$ & & \\
\hline
\end{tabular}

Note. For interactions and main effects, $\alpha=.008333$; for subsequent tests of simple effects, $\alpha=0.05$. Text in grey represents non-significant results. $*$ Welch-correction for unequal variances applied (when Levene's test for unequal variances was significant and largest group was more than 1.5 times as large as smallest group). 
Table S13.

Sample details Study 4.

\begin{tabular}{lllllll}
\hline Respondent group & $\mathrm{N}$ & $\begin{array}{l}\text { Mean Age } \\
\text { (years) }\end{array}$ & $\begin{array}{l}\text { SD Age } \\
\text { (years) }\end{array}$ & $\begin{array}{l}\text { Range Age } \\
\text { (years) }\end{array}$ & $\begin{array}{l}\text { Response rate } \\
(\%)\end{array}$ & $\begin{array}{l}\text { Response rate after cleaning } \\
(\%)\end{array}$ \\
\hline Male scientists & 711 & 45.1 & 11.9 & $25-86$ & $*$ & $*$ \\
Female scientists & 286 & 41.8 & 10.3 & $24-77$ & $*$ & $*$ \\
\hline Total & 1418 & & & & 11.99 & 7.62 \\
\hline
\end{tabular}

Note. *Response rates cannot be computed for the two respondent groups separately because we did not know scientists' gender beforehand. The response rate is based on the total number of responses by the total number of e-mails sent (for details see https://osf.io/3nepx/). 
Table S14.

Scale reliabilities Study 4.

\begin{tabular}{lll}
\hline Scale & $\begin{array}{l}\text { Cronbach's } \\
\text { Alpha }\end{array}$ & $95 \% \mathrm{CI}$ \\
\hline Objectivity & .62 & $.55 ; .69$ \\
Rationality & .80 & $.75 ; .86$ \\
Open-mindedness & .70 & $.63 ; .76$ \\
Intelligence & .64 & $.57 ; .71$ \\
Integrity & .80 & $.75 ; .86$ \\
Communality & .61 & $.54 ; .68$ \\
\hline
\end{tabular}

Note. $95 \% \mathrm{CI}=95 \%$ confidence interval. 
Table S15.

Correlation tables Study 4: correlations between the characteristics of the ideal scientist, by Respondent group.

\begin{tabular}{|c|c|c|c|c|c|c|}
\hline Male scientists & & & & & & \\
\hline Feature & 1 & 2 & 3 & 4 & 5 & 6 \\
\hline 1. Objectivity & 1 & & & & & \\
\hline 2. Rationality & $.65^{* * * *}$ & 1 & & & & \\
\hline 3. Open-mindedness & $.65^{* * * *}$ & $.65^{* * * *}$ & 1 & & & \\
\hline 4. Intelligence & $.37 * * *$ & $.44 * * *$ & $.35^{* * * *}$ & 1 & & \\
\hline 5. Integrity & $.60 * * *$ & $.65^{* * * *}$ & $.58 * * *$ & $.36 * * *$ & 1 & \\
\hline 6. Communality & $.55^{* * * *}$ & $.40^{* * * *}$ & $.47 * * *$ & $.29 * * *$ & $.57 * * *$ & 1 \\
\hline \multicolumn{7}{|l|}{ Female scientists } \\
\hline 1. Objectivity & 1 & & & & & \\
\hline 2. Rationality & $.59 * * *$ & 1 & & & & \\
\hline 3. Open-mindedness & $.62 * * *$ & $.60 * * *$ & 1 & & & \\
\hline 4. Intelligence & $.43 * * *$ & $.49 * * *$ & $.44 * * *$ & 1 & & \\
\hline 5. Integrity & $.66^{* * * *}$ & $.65 * * *$ & $.60 * * *$ & $.57 * * *$ & 1 & \\
\hline 6. Communality & $.50 * * *$ & $.41 * * *$ & $.50 * * *$ & $.43 * * *$ & $.60 * * *$ & 1 \\
\hline \multicolumn{7}{|l|}{ Overall } \\
\hline 1. Objectivity & 1 & & & & & \\
\hline 2. Rationality & $.63 * * *$ & 1 & & & & \\
\hline 3. Open-mindedness & $.64 * * *$ & $.63 * * *$ & 1 & & & \\
\hline 4. Intelligence & $.39 * * *$ & $.45 * * *$ & $.37 * * *$ & 1 & & \\
\hline 5. Integrity & $.62 * * *$ & $.65 * * *$ & $.58 * * *$ & $.42 * * *$ & 1 & \\
\hline 6. Communality & $.54 * * *$ & $.40 * * *$ & $.48^{* * * *}$ & $.33 * * *$ & $.58 * * *$ & 1 \\
\hline
\end{tabular}

Note. *significant at $\alpha=.05, * *$ significant at $\alpha=.01, * * *$ significant at $\alpha=.001$. All $p$-values are adjusted for multiple testing. 


\section{Table S16.}

Statistical analyses Study 4.

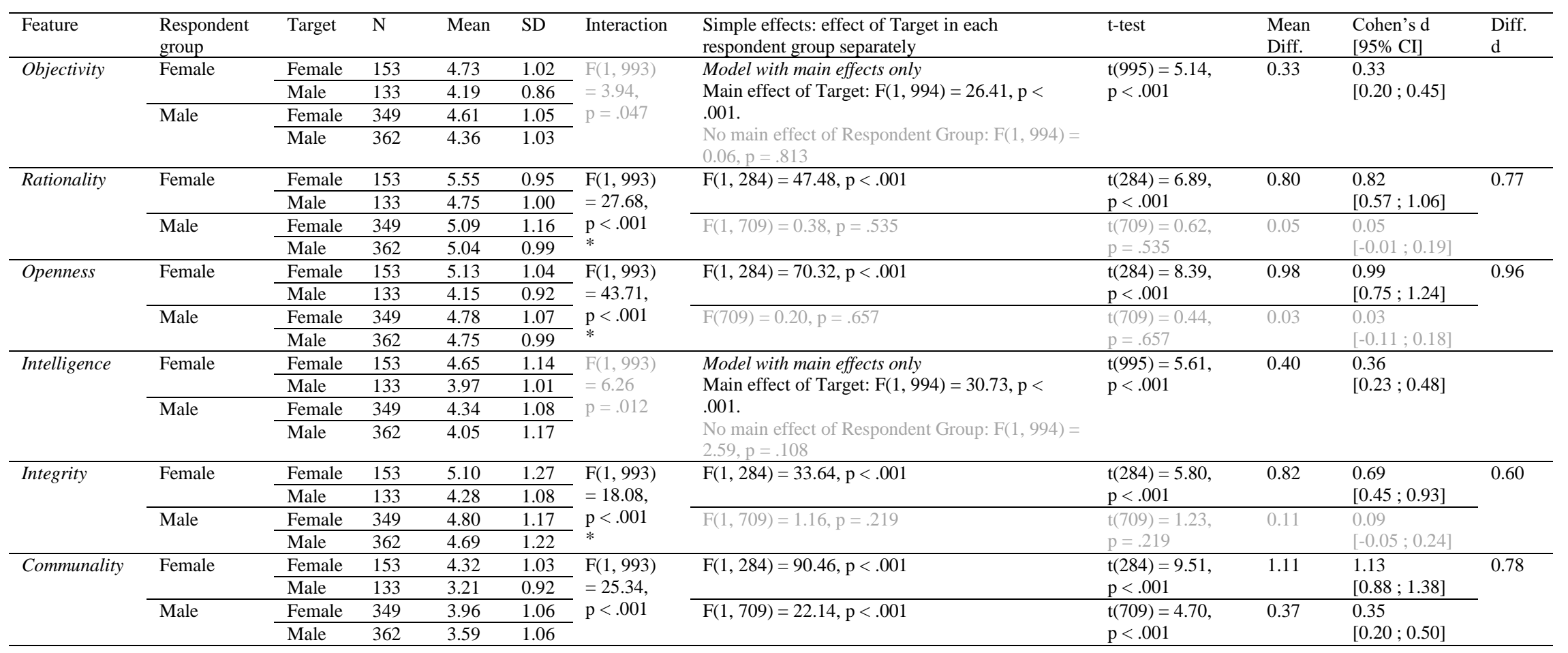

Note. For interactions and main effects, $\alpha=.008333$; for subsequent tests of simple effects, $\alpha=0.05$. Text in grey represents non-significant results. $*$ Welch-correction for unequal variances applied (when Levene's test for unequal variances was significant and largest group was more than 1.5 times as large as smallest group). 


\section{Materials}

$\underline{\text { Statements used in studies } 1,3 \text {, and } 4}$

In studies 1, 3 and 4, the following answering options were provided:

Strongly Disagree

O Disagree

Somewhat Disagree

O Neither Agree nor Disagree

O Somewhat Agree

O Agree

Strongly Agree 


\section{$\underline{\text { Study } 1}$}

\section{Scientist condition}

Below, you will read a series of statements about the typical scientist. By 'scientist', we mean a person who is trained in a science and whose job involves doing scientific research or solving scientific problems. For each statement, please indicate to what extent you agree or disagree. Important: please base your answers on how true you believe each statement is, so the statements do not refer to how you think scientists should behave.

1) A scientist is capable of suppressing personal biases in the interest of objective inquiry (Objectivity).

2) A scientist assesses relevant information without prejudicial distortions (Objectivity).

3) A scientist exhibits little emotionality with respect to his/her beliefs (Objectivity).

4) A scientist has excellent problem-solving skills (Rationality).

5) A scientist can readily discriminate between illogical and logical reasoning (Rationality).

6) A scientist is logical in his/her professional problem solving (Rationality).

7) A scientist suspends judgment when faced with insufficient or ambiguous information (Open-mindedness).

8) A scientist is generally willing to acknowledge evidence that goes against his/her beliefs (Open-mindedness).

9) A scientist is willing to change his/her beliefs when confronted with contrary evidence (Open-mindedness).

10) Standard measures of intelligence are a good predictor of the performance of a scientist (Intelligence).

11) Superior intelligence is a prerequisite for a successful career of a scientist (Intelligence).

12) A scientist has a very high IQ score (Intelligence).

13) A scientist conducts his/her work with integrity (Integrity).

14) A scientist does not engage in unethical behavior to advance his/her career (Integrity).

15) A scientist does not commit fraud in his/her work (Integrity).

16) A scientist does not withhold information from his/her colleagues to protect his/her own interests (Communality).

17) A scientist exhibits cooperative rather than competitive behavior (Communality).

18) A scientist is not interested in personal fame or recognition (Communality).

\section{Highly-educated condition}

Below, you will read a series of statements about the typical highly-educated person. By 'a highly-educated person', we mean a person who obtained a Bachelor's Degree or a Master's Degree or a Professional Degree and whose job requires this high level of education. For each statement, please indicate to what extent you agree or disagree. Important: please base your 
answers on how true you believe each statement is, so the statements do not refer to how you think highly-educated people should behave.

1) A highly-educated person is capable of suppressing personal biases in the interest of objective inquiry (Objectivity).

2) A highly-educated person assesses relevant information without prejudicial distortions (Objectivity).

3) A highly-educated person exhibits little emotionality with respect to his/her beliefs (Objectivity).

4) A highly-educated person has excellent problem-solving skills (Rationality).

5) A highly-educated person can readily discriminate between illogical and logical reasoning (Rationality).

6) A highly-educated person is logical in his/her professional problem solving (Rationality).

7) A highly-educated person suspends judgment when faced with insufficient or ambiguous information (Open-mindedness).

8) A highly-educated person is generally willing to acknowledge evidence that goes against his/her beliefs (Open-mindedness).

9) A highly-educated person is willing to change his/her beliefs when confronted with contrary evidence (Open-mindedness).

10) Standard measures of intelligence are a good predictor of the performance of a highlyeducated person (Intelligence).

11) Superior intelligence is a prerequisite for a successful career of a highly-educated person (Intelligence).

12) A highly-educated person has a very high IQ score (Intelligence).

13) A highly-educated person conducts his/her work with integrity (Integrity).

14) A highly-educated person does not engage in unethical behavior to advance his/her career (Integrity).

15) A highly-educated person does not commit fraud in his/her work (Integrity).

16) A highly-educated person does not withhold information from his/her colleagues to protect his/her own interests (Communality).

17) A highly-educated person exhibits cooperative rather than competitive behavior (Communality).

18) A highly-educated person is not interested in personal fame or recognition (Communality). 


\section{Study 3}

\section{PhD-student condition}

Below, you will read a series of statements about the typical PhD-student. By 'PhD-student', we mean a graduate student at an academic institution who is conducting scientific research for his/her doctoral dissertation. For each statement, please indicate to what extent you agree or disagree. Important: please base your answers on how true you believe each statement is, so the statements do not refer to how you think PhD-students should behave.

1) $\mathrm{A} \mathrm{PhD}$-student is capable of suppressing personal biases in the interest of objective inquiry (Objectivity).

2) $\mathrm{A} \mathrm{PhD-student} \mathrm{assesses} \mathrm{relevant} \mathrm{information} \mathrm{without} \mathrm{prejudicial} \mathrm{distortions}$ (Objectivity).

3) A PhD-student exhibits little emotionality with respect to his/her beliefs (Objectivity).

4) A PhD-student has excellent problem-solving skills (Rationality).

5) A PhD-student can readily discriminate between illogical and logical reasoning (Rationality).

6) A PhD-student is logical in his/her professional problem solving (Rationality).

7) A PhD-student suspends judgment when faced with insufficient or ambiguous information (Open-mindedness).

8) $\mathrm{A} \mathrm{PhD-student} \mathrm{is} \mathrm{generally} \mathrm{willing} \mathrm{to} \mathrm{acknowledge} \mathrm{evidence} \mathrm{that} \mathrm{goes} \mathrm{against} \mathrm{his/her}$ beliefs (Open-mindedness).

9) $\mathrm{A} \mathrm{PhD-student} \mathrm{is} \mathrm{willing} \mathrm{to} \mathrm{change} \mathrm{his/her} \mathrm{beliefs} \mathrm{when} \mathrm{confronted} \mathrm{with} \mathrm{contrary}$ evidence (Open-mindedness).

10) Standard measures of intelligence are a good predictor of the performance of a PhDstudent (Intelligence).

11) Superior intelligence is a prerequisite for a successful career of a $\mathrm{PhD}$-student (Intelligence).

12) A PhD-student has a very high IQ score (Intelligence).

13) A PhD-student conducts his/her work with integrity (Integrity).

14) $\mathrm{A} \mathrm{PhD}$-student does not engage in unethical behavior to advance his/her career (Integrity).

15) A PhD-student does not commit fraud in his/her work (Integrity).

16) $\mathrm{A} \mathrm{PhD-student} \mathrm{does} \mathrm{not} \mathrm{withhold} \mathrm{information} \mathrm{from} \mathrm{his/her} \mathrm{colleagues} \mathrm{to} \mathrm{protect}$ his/her own interests (Communality).

17) A PhD-student exhibits cooperative rather than competitive behavior (Communality).

18) A PhD-student is not interested in personal fame or recognition (Communality).

\section{Early-career scientist condition}

Below, you will read a series of statements about the typical early-career scientist. By 'earlycareer scientist', we mean a post-doctoral academic who obtained their PhD less than 10 years ago, and does not yet have tenure at a university or other academic institution. For each statement, please indicate to what extent you agree or disagree. Important: please base 
your answers on how true you believe each statement is, so the statements do not refer to how you think early-career scientists should behave.

1) An early-career scientist is capable of suppressing personal biases in the interest of objective inquiry (Objectivity).

2) An early-career scientist assesses relevant information without prejudicial distortions (Objectivity).

3) An early-career scientist exhibits little emotionality with respect to his/her beliefs (Objectivity).

4) An early-career scientist has excellent problem-solving skills (Rationality).

5) An early-career scientist can readily discriminate between illogical and logical reasoning (Rationality).

6) An early-career scientist is logical in his/her professional problem solving (Rationality).

7) An early-career scientist suspends judgment when faced with insufficient or ambiguous information (Open-mindedness).

8) An early-career scientist is generally willing to acknowledge evidence that goes against his/her beliefs (Open-mindedness).

9) An early-career scientist is willing to change his/her beliefs when confronted with contrary evidence (Open-mindedness).

10) Standard measures of intelligence are a good predictor of the performance of an earlycareer scientist (Intelligence).

11) Superior intelligence is a prerequisite for a successful career of an early-career scientist (Intelligence).

12) An early-career scientist has a very high IQ score (Intelligence).

13) An early-career scientist conducts his/her work with integrity (Integrity).

14) An early-career scientist does not engage in unethical behavior to advance his/her career (Integrity).

15) An early-career scientist does not commit fraud in his/her work (Integrity).

16) An early-career scientist does not withhold information from his/her colleagues to protect his/her own interests (Communality).

17) An early-career scientist exhibits cooperative rather than competitive behavior (Communality).

18) An early-career scientist is not interested in personal fame or recognition (Communality).

\section{Established scientist condition}

Below, you will read a series of statements about the typical established scientist. By 'established scientist', we mean a scientist who obtained their $\mathrm{PhD}$ more than 10 years ago, and has tenure at a university or other academic institution. For each statement, please indicate to what extent you agree or disagree. Important: please base your answers on how 
true you believe each statement is, so the statements do not refer to how you think established scientists should behave.

1) An established scientist is capable of suppressing personal biases in the interest of objective inquiry (Objectivity).

2) An established scientist assesses relevant information without prejudicial distortions (Objectivity).

3) An established scientist exhibits little emotionality with respect to his/her beliefs (Objectivity).

4) An established scientist has excellent problem-solving skills (Rationality).

5) An established scientist can readily discriminate between illogical and logical reasoning (Rationality).

6) An established scientist is logical in his/her professional problem solving (Rationality).

7) An established scientist suspends judgment when faced with insufficient or ambiguous information (Open-mindedness).

8) An established scientist is generally willing to acknowledge evidence that goes against his/her beliefs (Open-mindedness).

9) An established scientist is willing to change his/her beliefs when confronted with contrary evidence (Open-mindedness).

10) Standard measures of intelligence are a good predictor of the performance of an established scientist (Intelligence).

11) Superior intelligence is a prerequisite for a successful career of an established scientist (Intelligence).

12) An established scientist has a very high IQ score (Intelligence).

13) An established scientist conducts his/her work with integrity (Integrity).

14) An established scientist does not engage in unethical behavior to advance his/her career (Integrity).

15) An established scientist does not commit fraud in his/her work (Integrity).

16) An established scientist does not withhold information from his/her colleagues to protect his/her own interests (Communality).

17) An established scientist exhibits cooperative rather than competitive behavior (Communality).

18) An established scientist is not interested in personal fame or recognition (Communality). 


\section{Study 4}

\section{Male scientist condition}

Below, you will read a series of statements about the typical male scientist. For each statement, please indicate to what extent you agree or disagree. Important: please base your answers on how true you believe each statement is, so the statements do not refer to how you think male scientists should behave.

1) A male scientist is capable of suppressing personal biases in the interest of objective inquiry (Objectivity).

2) A male scientist assesses relevant information without prejudicial distortions (Objectivity).

3) A male scientist exhibits little emotionality with respect to his beliefs (Objectivity).

4) A male scientist has excellent problem-solving skills (Rationality).

5) A male scientist can readily discriminate between illogical and logical reasoning (Rationality).

6) A male scientist is logical in his professional problem solving (Rationality).

7) A male scientist suspends judgment when faced with insufficient or ambiguous information (Open-mindedness).

8) A male scientist is generally willing to acknowledge evidence that goes against his beliefs (Open-mindedness).

9) A male scientist is willing to change his beliefs when confronted with contrary evidence (Open-mindedness).

10) Standard measures of intelligence are a good predictor of the performance of a male scientist (Intelligence).

11) Superior intelligence is a prerequisite for a successful career of a male scientist (Intelligence).

12) A male scientist has a very high IQ score (Intelligence).

13) A male scientist conducts his work with integrity (Integrity).

14) A male scientist does not engage in unethical behavior to advance his career (Integrity).

15) A male scientist does not commit fraud in his work (Integrity).

16) A male scientist does not withhold information from his/her colleagues to protect his own interests (Communality).

17) A male scientist exhibits cooperative rather than competitive behavior (Communality).

18) A male scientist is not interested in personal fame or recognition (Communality).

\section{Female scientist condition}

Below, you will read a series of statements about the typical female scientist. For each statement, please indicate to what extent you agree or disagree. Important: please base your answers on how true you believe each statement is, so the statements do not refer to how you think female scientists should behave. 
1) A female scientist is capable of suppressing personal biases in the interest of objective inquiry (Objectivity).

2) A female scientist assesses relevant information without prejudicial distortions (Objectivity).

3) A female scientist exhibits little emotionality with respect to her beliefs (Objectivity).

4) A female scientist has excellent problem-solving skills (Rationality).

5) A female scientist can readily discriminate between illogical and logical reasoning (Rationality).

6) A female scientist is logical in her professional problem solving (Rationality).

7) A female scientist suspends judgment when faced with insufficient or ambiguous information (Open-mindedness).

8) A female scientist is generally willing to acknowledge evidence that goes against her beliefs (Open-mindedness).

9) A female scientist is willing to change her beliefs when confronted with contrary evidence (Open-mindedness).

10) Standard measures of intelligence are a good predictor of the performance of a female scientist (Intelligence).

11) Superior intelligence is a prerequisite for a successful career of a female scientist (Intelligence).

12) A female scientist has a very high IQ score (Intelligence).

13) A female scientist conducts her work with integrity (Integrity).

14) A female scientist does not engage in unethical behavior to advance her career (Integrity).

15) A female scientist does not commit fraud in her work (Integrity).

16) A female scientist does not withhold information from her colleagues to protect her own interests (Communality).

17) A female scientist exhibits cooperative rather than competitive behavior (Communality).

18) A female scientist is not interested in personal fame or recognition (Communality). 